\title{
Basınçlı döküm prosesinde iki farklı soğutma kanallı kalıpların döküm-kalıp arayüzey ısı transfer katsayısının nümerik olarak incelenmesi
}

\author{
Numerical investigation of casting-mold interfacial heat transfer coefficient of molds with \\ two different cooling channels in pressure casting process
}

\author{
Mehmet KAN ${ }^{* 1, a}$, Murat KORU ${ }^{2, b}$ Osman İPEK $^{1, \mathrm{c}}$ \\ ${ }^{1}$ Süleyman Demirel Üniversitesi, Mühendislik Fakültesi, Makine Mühendisliği Bölümü, 32260, Isparta \\ ${ }^{2}$ Isparta Uygulamalı Bilimler Üniversitesi, Teknoloji Fakültesi, Makine Mühendisliği Bölümü, 32200, Isparta
}

Öz

Basınçlı dökümde, döküm-kalıp arayüzey ısı transfer katsayısı (AITK) kalıp ve dökümü yapılan parçada meydana gelen yapısal değişimler ile katılaşma hızını etkileyen önemli unsurdur. AITK, döküm-kalıp arasında meydana gelen isı transferi, katılaşma hızı, ergiyik metal ve kalıp sıcaklıkları, döküm ve kalıp malzemesi gibi birçok faktörlerden bağlı olarak değişim gösterir. Bu çalışmada, basınçlı döküm prosesinde klasik soğutma kanallı metal kalıp ile özgün soğutma kanallı metal kalıp için döküm-kalıp AITK'nın zamana bağlı değişimi nümerik olarak incelenmiştir. Basınçlı döküm prosesinde; döküm malzemesi olarak A16061 alüminyum alaşımı kullanılacak metal kalıplar için AITK, sıcaklık dağılımı ve 1Sı transferi bakımından karşılaştııılması yapılmıştır. 0.5-10 s zaman aralığında yapılan analizlerde bu kalıplar ile ergiyik metal arasındaki AITK ve sıcaklıklar hesaplanmıştır. Özgün soğutma kanallı kalıpta klasik soğutma kanallı kalıba göre 1.33 kat daha iyi sıcaklık düşüusü gerçekleşmiştir. Özgün soğutma kanallı kalıpta klasik soğutma kanallı kalıba kıyasla 2.23 kat daha iyi 1sı transfer katsayısı olduğu hesaplanmıştır. Sonuç olarak; özgün soğutma kanallı kalıpta AITK, sıcaklık dağılımı ve ısı transferinin daha iyi olduğu gözlemlenmiştir.

Anahtar kelimeler: Arayüzey ısı transfer katsayısı, Basınçlı döküm, HAD, Kalıp

\begin{abstract}
In the pressure casting, the casting-mold interface heat transfer coefficient (IHTC) is a significant element affecting the solidification rate with the structural changes occurring in the mold and the part being cast. IHTC varies depending on many factors such as heat transfer between molten metal and mold, solidification rate, casting and mold temperatures, casting, and mold material. In this study, the time-dependent variety of IHTC of casting for a conventional cooling channel metal mold and an original cooling channel metal mold in the pressure casting process was numerically investigated. In the pressure casting process, IHTC for metal molds using Al6061 aluminum alloy as casting material was compared in terms of temperature distribution and heat transfer. The IHTC and temperatures between these molds and the molten metal were calculated in the analyzes made in the 0.5-10s time interval. In the original cooling channel mold, the temperature drop was 1.33 times better than the conventional cooling channel mold. It has been calculated that the original cooling channel mold has a 2.23 times better heat transfer coefficient compared to the conventional cooling channel mold. As a result, it was observed that IHTC, temperature distribution and heat transfer were better in the original cooling channel mold.
\end{abstract}

Keywords: Interface heat transfer coefficient, High pressure casting, CFD, Mold

\footnotetext{
${ }^{* a}$ Mehmet KAN; mehmetkan@sdu.edu.tr, Tel: (0539) 58753 67, orcid.org/0000-0001-7336-1489

${ }^{\mathrm{b}}$ orcid.org/0000-0002-7069-1615 $\quad{ }^{\mathrm{c}}$ orcid.org/0000-0002-6949-645X
} 


\section{Giriş \\ 1. Introduction}

Basınçlı döküm prosesinde döküm işlemi, ergiyik metalin yüksek basınç etkisinde kalıbı doldurduktan sonra ergiyik metalin katılaşmasıyla gerçekleştirilir. Sıvı metal kalıp boşluğunu doldurmasıyla ergiyik metal ile kalıp arasında 1sı transferi meydana gelmektedir. Kalıp ve döküm malzemesi arasinda meydana gelen 1si transferi sonucunda döküm-kalıp arayüzeyinde 1sıl temas direnci oluşur. Taşınım ısı transfer katsayısına benzeyen $\left(h_{c}\right)$ büyüklüğü olarak ifade edilen bu direnç, 1sı transferini ve katılaşma hızını etki eder. Is1 transfer katsayısı zamana bağlı değişim gösterdiğinden dolayı döküm-kalıp arasında meydana gelen 1S1 transferinde 1s1 temas direncinin belirlenmesi oldukça güçtür. Isıl temas direnci kalıp ve döküm prosesleri için önemli bir parametredir.

Son zamanlarda, döküm işlemi ve kalıp tasarımına yönelik döküm optimizasyon çalışmalarında simülasyon programlarının kullanımı yaygınlaşmıştır. Birçok endüstriyel döküm işlemlerinde kalıp ve döküm tasarım simülasyonları öncelikle bilgisayar ortamında yapılarak üretimde meydana gelecek hatalar indirgenmeye çalışılmaktadır. Döküm simülasyon çalışmalarında döküm-kalıp AITK, katılaşma sürecinin irdelenmesi ve döküm optimizasyon bakımından oldukça önemlidir. Döküm-kalıp AITK'nın belirlenmesi, ergiyik metal ile kalıp arasinda meydana gelen isi transferine, kalıp ve döküm malzemesinin termofiziksel özelliklerine, kalıp-döküm sıcaklıklarına bağlı olarak değişmektedir. Katılaşma sürecinde katılaşan ergiyik metalin özgül ve ergime gizli 1sısının 1sıl temas dirençleriyle etkileşimi sonucu kalıba aktarılır. Katılaşma sürecinde 1sı transferinin büyük bölümü iletimle gerçekleşirken, yüksek sıcaklığın etkisiyle 1şınım ve taşınımla da gerçekleşmektedir (Zhang vd., 2007; Chen, 2003; Akar vd., 2008; Dour vd., 2005; Şahin vd., 2006; Hamasaiid vd., 2010; Michel vd., 1995; Reddy ve Beckermann, 1993; Loulou vd., 1999; Ho, ve Pehlke, 1985)

Basınçl1 dökümde, dökümü etkileyen faktörler ve döküm-kalıp AITK ile ilgili çalışmalar yapılmıștır. Farklı kalıplara döküm işleminde ve çeşitli alaşımlarında 1sı transferi üzerinde kalıp sıcaklığının etkisini incelemiştir. Isı transferinin ve kalıp sicaklığının artması ile AITK arttığını gözlemlemişlerdir (Hallam ve Griffiths 2004; Bouchard vd., 2009; Gozlan ve Bamberger, 1987; Sabau ve Wu, 2007; Taha vd, 2001; Arunkumar vd., 2008; Coates ve Argyropoulos, 2007). Ergiyik metalin kalıba dökülmesiyle; kalıbın yüzey pürüzlülüğü, proses basıncı, ergiyik metalin döküm hızı, kalıp ve döküm sıcaklığının etkisiyle AITK'nın etkilendiğini söylemişlerdir. Ergiyik metalin kalıba temas ettiği alanlarda aşırı soğumasından dolayı AITK'nın azaldığı bildirilmiştir (Akar vd., 2013; Srinivasan, 1982; İpek ve Koru, 2011; Dong vd., 2011; 1khchy vd., 2012). Basınçlı dökümde, kalıp döküm işleminden önce ön 1sıtma işlemine tabi tutulmaktadır. Döküm başladıktan sonra, ergiyik sıcaklığının etkisiyle kalıbın sıcaklığı artmaya devam eder. Döküm sırasında kalıp sıcaklığı sabit olmamaktadır. Bu yüzden kalıbın sıcaklığını belli bir sicaklık değerlerinde tutmak için kalıp soğutma sistemi kullanılmaktadır. Soğutma sistemiyle hem kalıp soğutulmakta hem de ergiyik metalin katılaşması gözlemlenmektedir. Yaptıkları soğutma sistemleriyle kalıbın sıcaklık dağılımını, katılaşma hızını, soğuma sürecini ve meydana gelen 1S1 transferini incelemişlerdir (Santos vd., 2004; Garza vd., 2003; Gafur vd., 2003; Durat vd., 2006; Christy vd., 2010; Silva vd., 2011).

$\mathrm{Bu}$ araştırmalar dikkate alınarak yapılan bu çalışmada, klasik soğutma kanallı kalıp ve özgün soğutma kanallı kalıp için, farklı zaman aralıklarına göre AITK'nın belirlenmesi amaçlanmıştır. $\mathrm{Bu}$ amaçla; döküm ve kalıp malzemesi olarak Al6061 alüminyum alaşımı ve H13 çeliği seçilmiştir. Çalışmada, ergiyik metalin sicaklığ $1973 \mathrm{~K}$, kalıbın sicaklığ $1543 \mathrm{~K}$ olarak alınmıştır. Ayrıca soğutma sıvısı olarak 1sı transfer yağ1 kullanılmıştır. Basınçlı dökümde, dökümkalıp AITK'nın zamana bağlı değişimi nümerik olarak incelenmiş ve kalıp 1s1 transfer mekanizmaları belirlenmiştir. 0.5-10 s zaman aralığında yapılan analizlerde bu kalıplar ile ergiyik metal arasındaki AITK ve sicaklıklar hesaplanmıştır. Sonuç olarak; özgün soğutma kanallı kalıpta AITK, sicaklık dağılımı ve 1sı transferinin daha iyi olduğu gözlemlenmiştir.

\section{Materyal ve metot}

\section{Material and method}

Döküm esnasında; döküm-kalıp AITK, kalıp içindeki döküm malzemesi ve kalıbın sıcaklık dağılımı, döküm sıcaklığı, kalıp sıcaklığı ve katılaşma sırasındaki sınır şartları gibi parametrelerin uygun şekilde belirlenmesi hem enjeksiyon ürünü kalitesi hem de prosesin performansinda etkili olan parametrelerdir. $\mathrm{Bu}$ çalışmada, basınçlı döküm prosesinde klasik soğutma kanallı metal kalıp ile özgün soğutma kanallı metal kalıp için döküm-kalıp arayüzey 1sı transfer katsayısının zamana bağlı değişimi 
nümerik olarak incelenmiştir. Bu amaçla, A16061 alüminyum alaşımının basınçlı döküm prosesinde kullanılacak metal kalıplar için döküm-kalıp AITK, sıcaklık dağılımı ve 1 sı transferi nümerik olarak hesaplanmıştır. Şekil 1'de görüldüğü gibi metal kalıbın katı modelinin simetri kalıp parçaları kompakt olarak tasarlanmıştır. Döküm parçası için optimum soğutma yapılması amaciyla klasik soğutma kanalları tasarlanmıştır. Tasarlanan soğutma kanallarının, 1S1 transferine etkisi ve ergiyik metalin katılaşması simetri durumundan dolayı kalıbın yarısı için nümerik olarak irdelenmiştir.
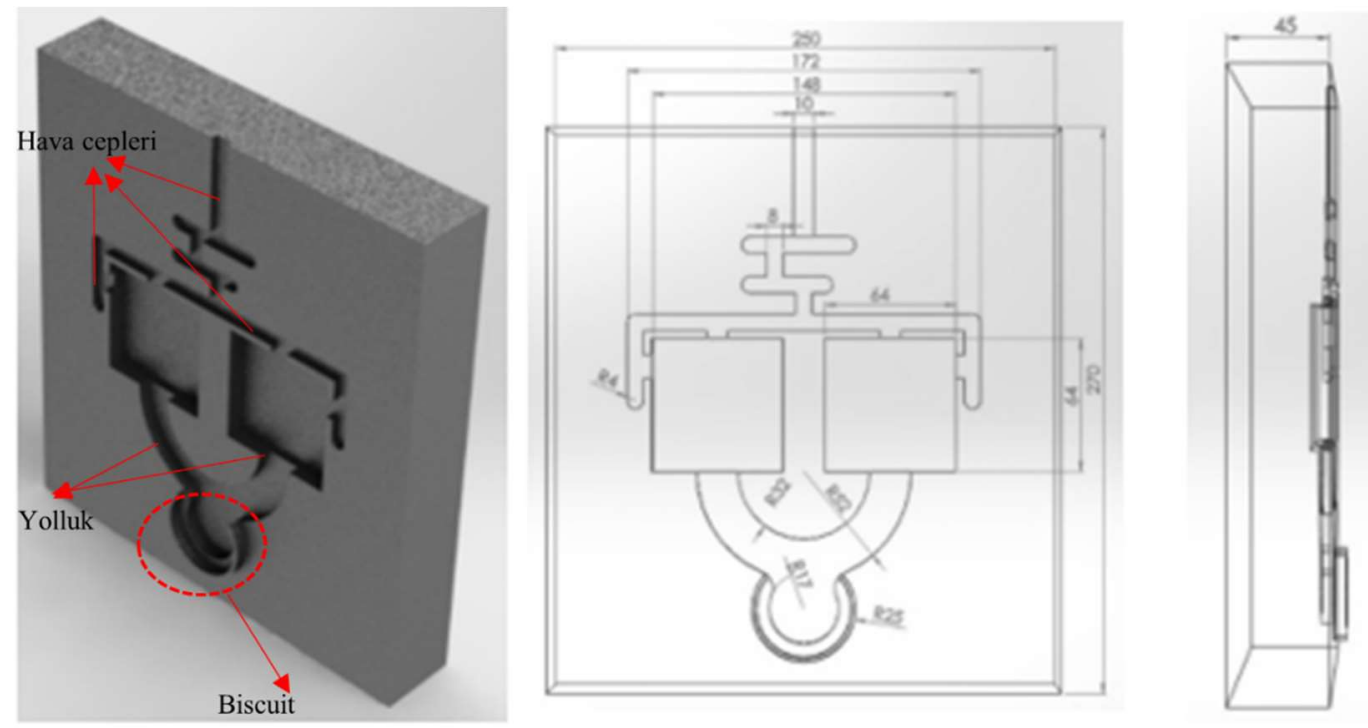

Şekil 1. Metal kalıp 3D çizimi

Figure 1. Metal mold $3 D$ drawing

2.1. Ansys-Fluent yazılımında kullanılan temel denklemler ve analiz çözümlemesindeki metotlar

2.1. Basic equations used in Ansys-Fluent software and methods in analysis analysis

HAD (Hesaplamalı Akışkanlar Dinamiği) analizlerinde sayısal ağ yapısı oluşturulmuştur.
Klasik soğutma kanallı ve özgün soğutma kanallı metal kalıbın akış hacmi ağ modelinde tetrahedral elemanlar kullanılmıştır. $\mathrm{Bu}$ modelde ortalama 6541221 elaman, 1449372 adet düğüm noktası bulunmaktadır. Şekil 2' de görüldüğü gibi metal kalıpta dolaşan akışkana ait akış hacmi modeli oluşturulmuştur.

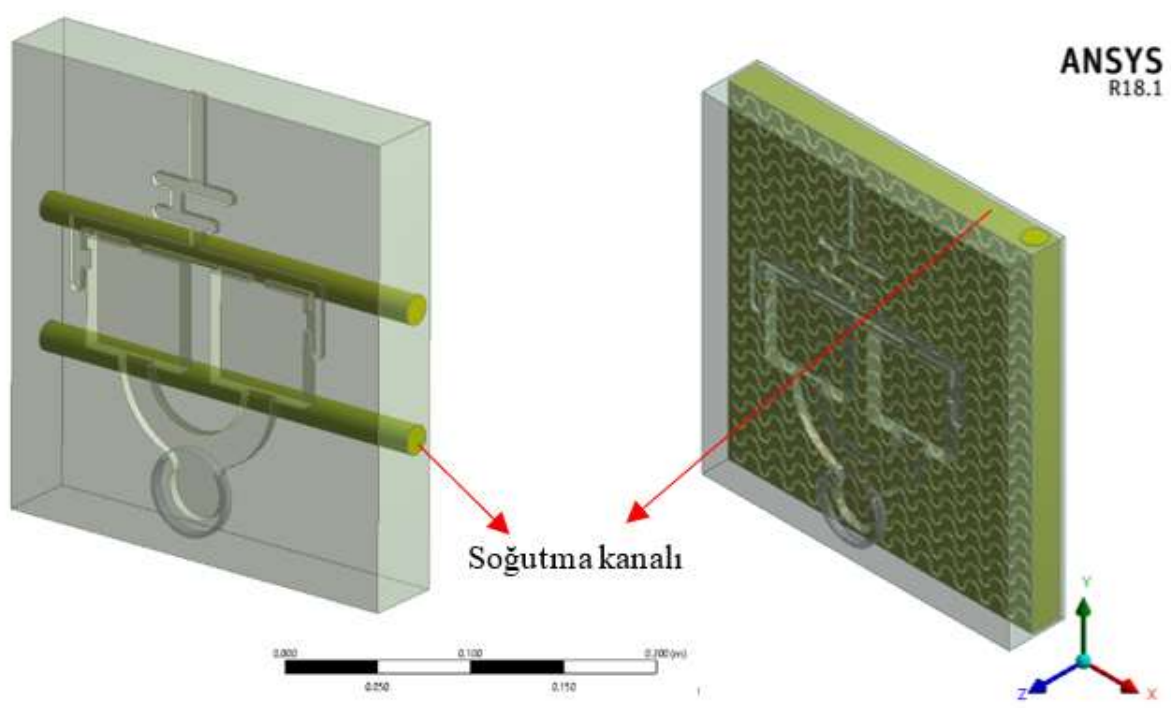

Şekil 2. Soğutma kanalı akış hacmi

Figure 2. Cooling channel flow volume 
Yapılan bu tasarım için Şekil 3'te verilen ağ yapısına göre CFD analizleri soğutma kanalı ısıl ve hidrodinamik davranışı için Ansys-Fluent yazılımı kullanılarak gerçekleştirilmiştir.
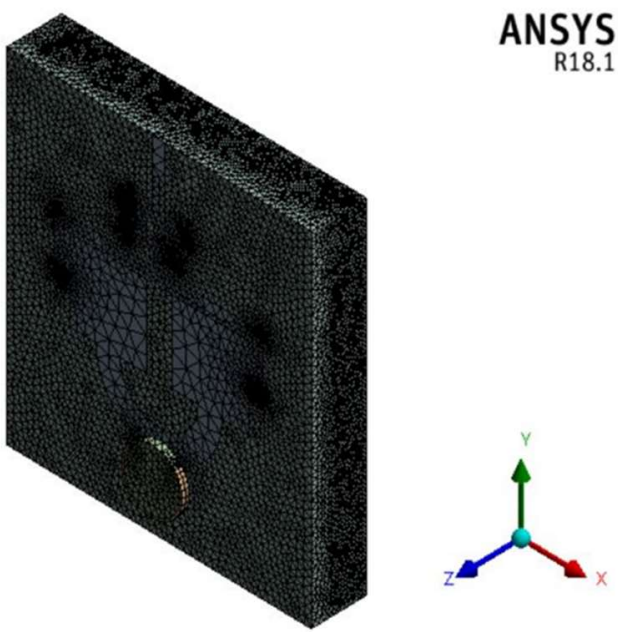

Şekil 3. Kalıpların ağ yapısı

Figure 3. Network structure of the molds

Sonlu hacimler metoduna dayanan bu yöntemde Ansys-Fluent veya diğer simülasyon programları kullanılmaktadır. Programlardan alınan ağ yapısı dosyalarına sınır şartları ve parametreler uygulanarak sistemin çözümü yapılmaktadır. Sayısal çalışmada, üç boyutlu ve zamana bağlı kütlenin korunumu, momentum ve enerji denklemleri kullanılarak analizler gerçekleştirilmektedir. Ansys-Fluent programı, sistemi çözüme ulaştırmak için geri planda aşağıdaki denklemleri kullanmaktadır (Ansys, 2018).

Süreklilik denklemi Denklem 1'de gösterilmiştir.

$\frac{\partial \rho}{\partial t}+\nabla \cdot(\rho \vec{v})=0$

Momentum denklemi ise Denklem 2' de verilmiștir:

Tablo 1. Nümerik hesaplamalarda kullanılan yaklaşımlar (Ansys, 2018)

Table 1. Approaches used in numerical calculations (Ansys, 2018)

\begin{tabular}{ll}
\hline Simülasyon koşulu & Zamana bağlı durum (Transient-state) \\
\hline Çözücü tipi & Basınca dayalı çözücü \\
Viskoz model & Standard k $-\varepsilon$ türbülans modeli \\
Hız-basınç etkileşimi & COUPLED algoritması \\
Ayrıklaştırma yöntemi & İkinci dereceden merkezi farklar metodu \\
Basınç, momentum ve enerji denklemleri & İkinci dereceden merkezi farklar metodu \\
Türbülans kinetik enerji ve türbülans dağılım oranı & İkinci dereceden merkezi farklar metodu \\
COUPLED (Birleşik) algoritması & Poseido-Transient Explicit (açı) çözüm \\
\hline
\end{tabular}

Sonlu hacimler ile ilgili yapılan sayısal çalışmalarda düzgün ve kaliteli bir ağ oluşturmak
$\mathrm{S}=\frac{(1-\beta)^{2}}{\beta^{3}+\varepsilon} A_{m u s h}\left(\vec{v}-\overrightarrow{v_{p}}\right)$

Burada $\beta, 0$ ile 1 arasında değișmektedir. 0 katı fazı gösterirken 1 sıv1 fazı temsil etmektedir. $0<\beta<1$ bölgesi ise musy bölgesi olarak tanımlanmaktadır. Ayrıca A $\left(\mathrm{m}^{2}\right)$ alanı ve $\vec{v}(\mathrm{~m} / \mathrm{s})$ akış hızını ifade etmektedir.

Enerjinin korunumu denklemi (Denklem 3) aşağıda verilmiştir.

$\frac{\partial}{\partial \mathrm{t}}(\rho \mathrm{H})+\nabla \cdot \rho \vec{v} \mathrm{H}=\nabla \cdot(\mathrm{k} \nabla \mathrm{T})+\mathrm{S}$

Burada; $\mathrm{H}$ entalpi $(\mathrm{J}) ; \rho$ yoğunluk $\left(\mathrm{kg} / \mathrm{m}^{3}\right), \vec{v}$ akış hızı $(\mathrm{m} / \mathrm{s})$ ve $S_{\mathrm{E}}$ kaynak terimini $\left(\mathrm{J} / \mathrm{m}^{3} \mathrm{~s}\right)$ ifade etmektedir.

Tablo 1'de nümerik hesaplamalarda kullanılan yaklaşımlar belirlenmiştir (Ansys, 2018). sonuçların doğruluğu açısından çok önemlidir. Bu yüzden sayısal çalışmalarda ă̆ kalitesi 
aranmaktadır. Ancak analizi yapılan geometrilerin karmaşıklığ 1 arttıkça bu ağ kalitesini elde etmek zorlaşmaktadır. Sayısal çalışmaların doğrulanmasında başvurulan yöntemlerden birisi de ağdan bağımsızlık testleridir. Sayısal çözümlemede ağ sayısı artmasına rağmen sonuç belli bir değerden sonra değişmiyorsa, çözümlemede ağdan bağımsızlık elde edilmektedir. Analizlerde standart duvar fonksiyonları modeli kullanılmıştır. Bu modelde ve türbülanslı akışlarda, sınır tabakası belirlemek için $(30<\mathrm{Y}+<300)$ aralığında olması beklenmektedir. $\mathrm{Y}+$ değerinin 30'a yakın olması beklemektedir (Ansys, 2018). Şekil 4'te ağ bağımsızlık test grafiği verilmiştir.

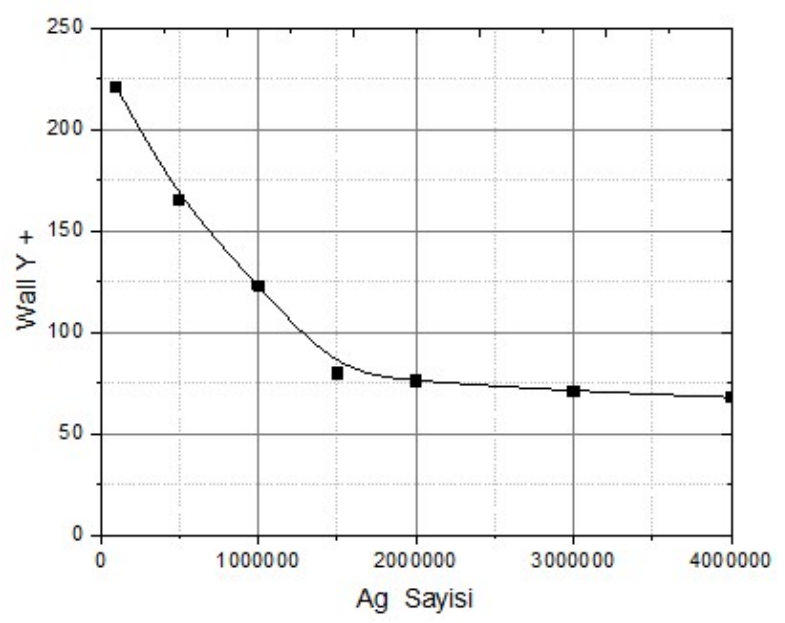

Şekil 4. Ağ bağımsızlık test grafiği

Figure 4. Network independence test plot

Ağdan bağımsızlık testleri sırası 7 farklı ağ sayılarında yapılmıştır. Şekil 4'te görüleceği üzere 1449372 düğüm noktasında yapılan çözümlemelerden sonra Wall $\mathrm{Y}+$ değerinde çok fazla değişim gözlemlenmemiştir. Bu yüzden bu modelde 6541221 elaman, 1449372 adet düğüm noktası bulunmaktadır.

\subsection{Metal kalıbın matematiksel analizi}

\subsection{Mathematical analysis of metal mold}

Yapılan çalışmada; döküm esnasında meydana gelen faz değişimi ve malzeme özellikleri göz önünde bulundurularak, ergiyik metalin katılaşması ve kalıpta meydana gelen 1sı transferi için doğrusal olmayan zamana bağlı denklemler kullanılmıştır. Ergiyik metalin kalıba dökümüyle katılaşma ve soğuma süreci boyunca kalıba ısı akışı gerçekleşir. Döküm ve kalıp malzemesinin her ikisinde de 1s1 akıs1 arayüzey ve arayüzeyi takip eden ilk düğüm noktalarındaki sıcaklık farkları $\left(\Delta \mathrm{T}=\mathrm{T}_{\mathrm{K}}-\mathrm{T}_{\mathrm{K}-1)}\right)$ ile Denklem 4 yardımıyla hesaplanır.

$\dot{\mathrm{q}}=-\mathrm{k} \frac{\Delta T}{\Delta l}$

Burada k 1s1 iletim katsayıs1 (W/mK), $\Delta \mathrm{l}(\mathrm{mm})$ herhangi bir zaman aralığında iki nokta arasındaki mesafeyi göstermektedir. Daha sonra Denklem 5'ten döküm parça-kalıp AITK hesaplanır.

$h=\frac{\dot{q}}{T_{D}-T_{K}}$

Burada h AITK $\left(\mathrm{W} / \mathrm{m}^{2} \mathrm{~K}\right), \dot{q}$ birim zamanda birim yüzeyden geçen $1 \mathrm{~s} 1$ akısı $\left(\mathrm{W} / \mathrm{m}^{2}\right), \mathrm{T}_{\mathrm{D}}$ ve $\mathrm{T}_{\mathrm{K}}$ sırası ile dökümün ve kalıbın yüzey sıcaklığıdır (K).

Şekil 5'te Kalıp-döküm malzemesi arayüzeyinde meydana gelen 1s1 transferi mekanizmasi gösterilmektedir.

Döküm alaşımı olarak Al6061 alüminyum alaşımı kullanılmıştır. Malzeme özellikleri sıcaklığa dolayısıyla zamana bağlı olarak değiştiği için zamana bağlı analiz yapılmıştır. Hesaplamalarda kullanılan kalıp ve döküm malzemelerinin termodinamik özellikleri Tablo 2'de verilmiştir. Analizlerde kullanılan Al6061 alüminyum alaşımının kimyasal bileşenleri Tablo 3'te verilmiştir. Isı transfer yağının özellikleri Tablo 4 'te verilmiştir. 


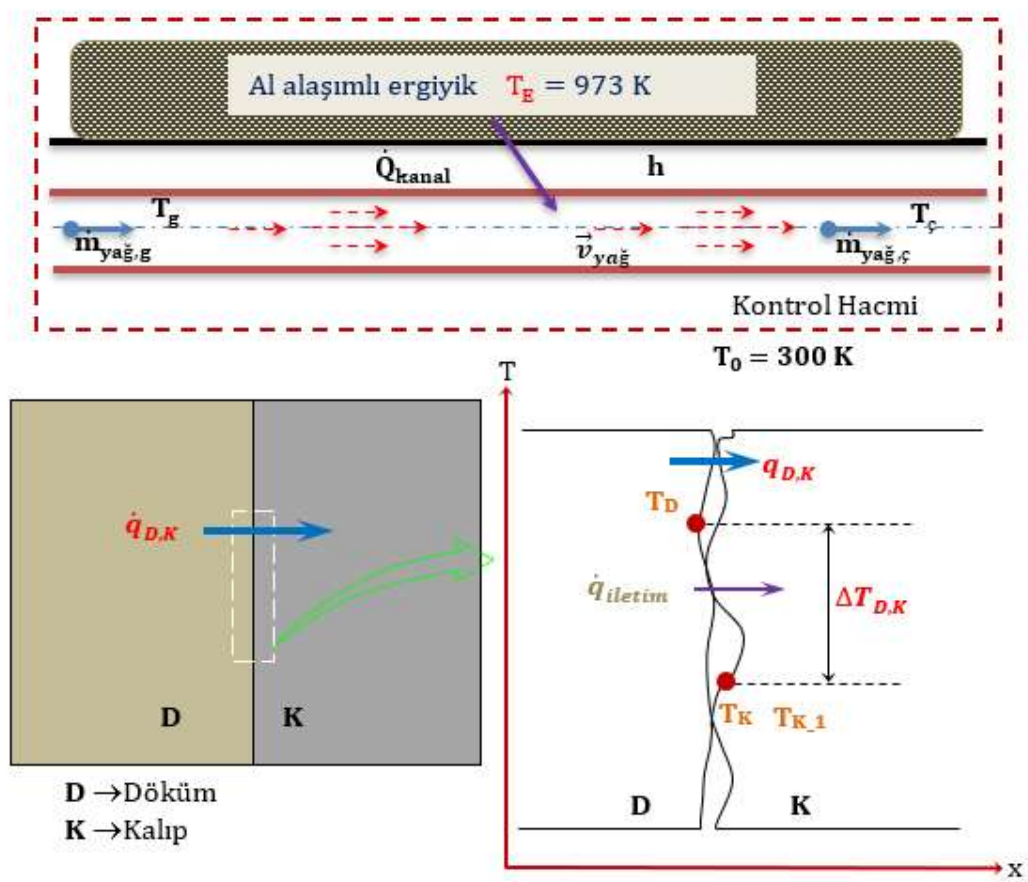

Şekil 5. Kalıp-döküm malzemesi arayüzeyinde meydana gelen 1s1 transferi mekanizması Figure 5. The heat transfer mechanism occurring at the mold-cast material interface

Tablo 2. Isı transfer katsayısının hesaplamalarında kullanılan malzemelerin termodinamik özellikleri (Dong vd., 2011)

Table 2. Thermodynamic properties of the materials used in the calculations of the heat transfer coefficient (Dong et al., 2011)

\begin{tabular}{cccc}
\hline Malzeme & $\mathrm{c}(\mathrm{J} / \mathrm{kgK})$ & $\mathrm{k}(\mathrm{W} / \mathrm{mK})$ & $\rho\left(\mathrm{kg} / \mathrm{m}^{3}\right)$ \\
\hline $\mathrm{H} 13$ & $435.37+0.2 \mathrm{~T}$ & $0.00029 \mathrm{~T}-26.85$ & $7866.86-0.3174 \mathrm{~T}$ \\
$\mathrm{Al} 6061$ & $656.35+0.8736 \mathrm{~T}-$ & $21.483+0.8048 \mathrm{~T}-0.0007 \mathrm{~T}^{2}$ & $2514.6+0.7597 \mathrm{~T}-$ \\
& $0.0004 \mathrm{~T}^{2}$ & & $0.0008 \mathrm{~T}^{2}$ \\
\hline
\end{tabular}

Tablo 3. Al6061 alaşımının kimyasal bileşenleri (Christy vd., 2010)

Table 3. Chemical components of Al6061 alloy (Christy et al., 2010)

\begin{tabular}{lllllllll}
\hline Element & $\mathbf{M g}$ & $\mathbf{F e}$ & $\mathbf{S i}$ & $\mathbf{C u}$ & $\mathbf{M n}$ & $\mathbf{V}$ & $\mathbf{T i}$ & $\mathbf{A l}$ \\
\hline $\mathrm{A} \breve{g} ı r l 1 k(\%)$ & 1.08 & 0.17 & 0.63 & 0.32 & 0.52 & 0.001 & 0.02 & Kal. \\
\hline
\end{tabular}

Tablo 4. Isı transfer yağının özellikleri (Therminol-XP) (Looser vd.,2014)

Table 4. Properties of heat transfer oil (Therminol-XP) (Looser et al., 2014)

\begin{tabular}{cccccc}
\hline $\begin{array}{c}\text { Özgül ısı } \\
(\mathrm{kJ} / \mathrm{kgK})\end{array}$ & $\begin{array}{c}\text { Yoğunluk } \\
\left(\mathrm{kg} / \mathrm{m}^{3}\right)\end{array}$ & $\begin{array}{c}\text { Viskozite } \\
(\text { Mpa s })\end{array}$ & $\begin{array}{c}\text { Isll } \\
\text { İletkenlik } \\
(\mathrm{W} / \mathrm{mK})\end{array}$ & $\begin{array}{c}\text { Termal gen. } \\
\text { katsayısı } \\
\left(\mathrm{K}^{-1}\right)\end{array}$ & $\begin{array}{c}\text { Çalışma } \\
\text { Sıcaklığ }(\mathrm{K})\end{array}$ \\
\hline 1.85 & 875 & 22.7 & 0.124 & 0.00089 & $253-600 \mathrm{~K}$ \\
\hline
\end{tabular}

\section{Bulgular}

3. Results

Yapılan analizler, simetri kompakt kalıbın tamamı için 3 D soğutma kanalı, metal kalıp çekirdeği ve ergiyik metalin sicaklık dağılımı belirlemek amacıyla zamana bağlı olarak ve 10 .s sonuna kadar yapılmış olup, ergiyik metal katılaşma hızı da incelenmiştir. Şekil 6'da, klasik soğutma kanalı için dökümden sonraki ilk 0.5 - $10 \mathrm{~s}$ aralıklarındaki ergiyik metal boyunca sıcaklık dağılım konturlarının zamana bağlı olan değişimleri verilmiştir. 

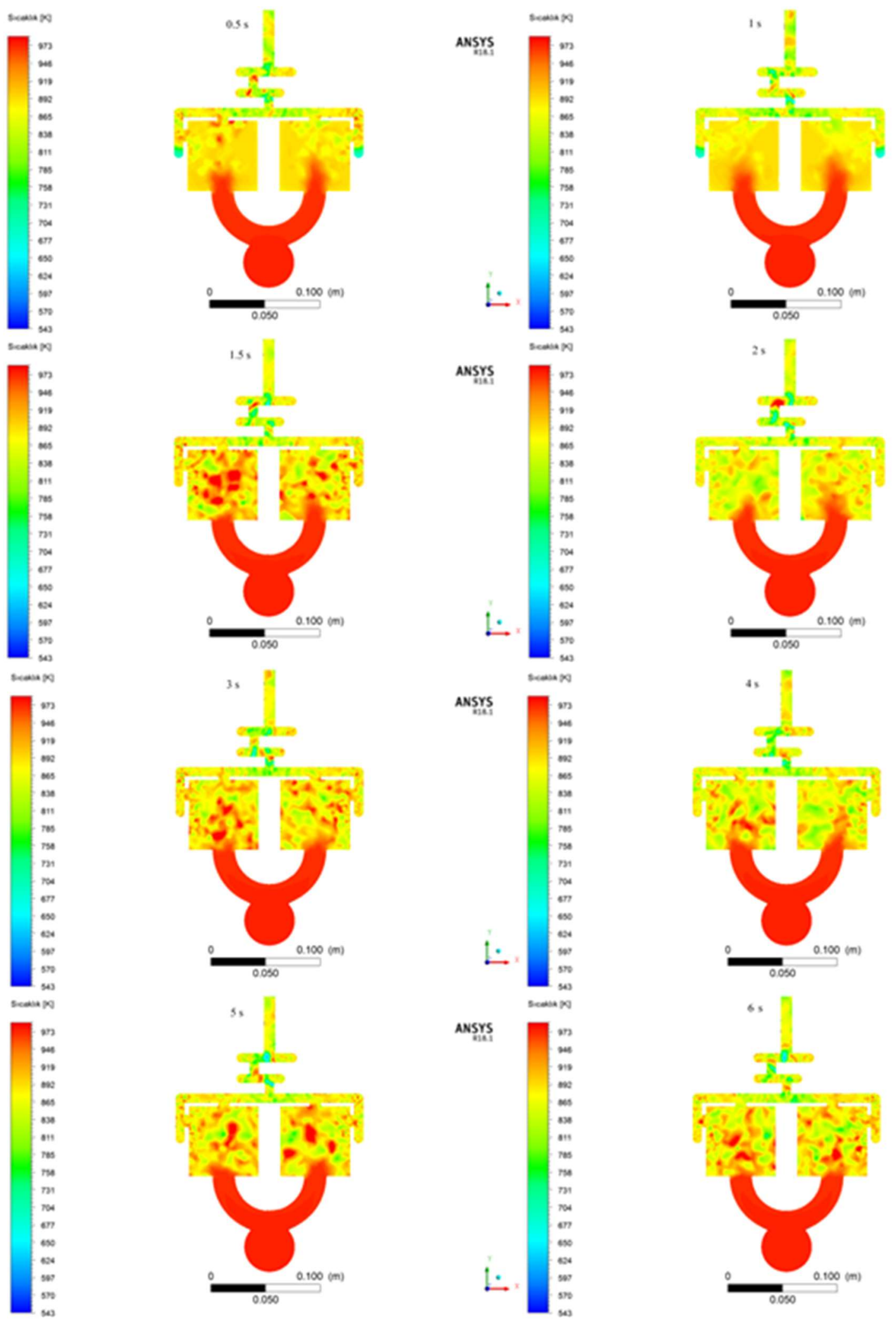

ANSYS

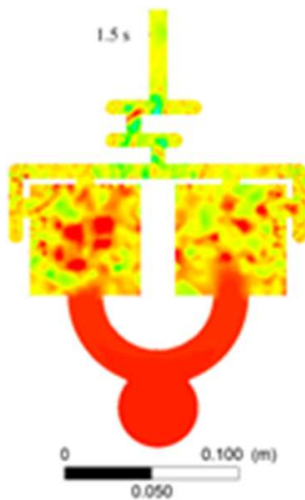

ANSYS
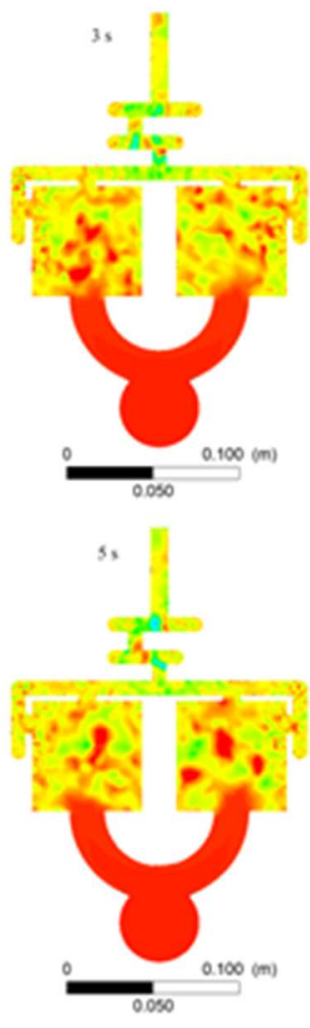
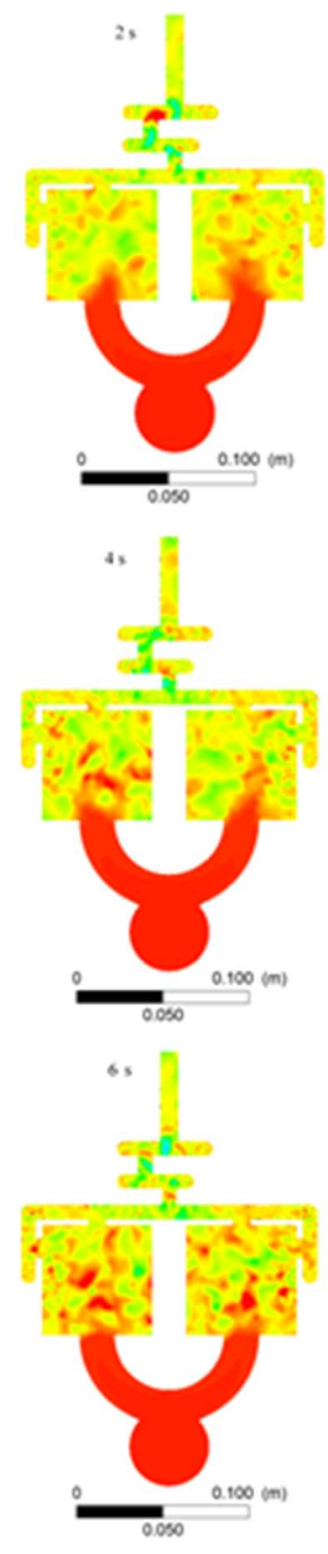

$\therefore$

ANSYS

ansys
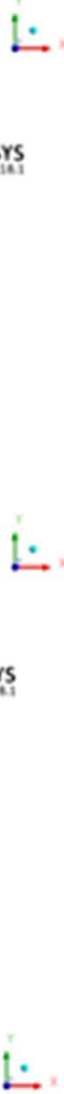

aNsYS

$\stackrel{-}{-}$ 

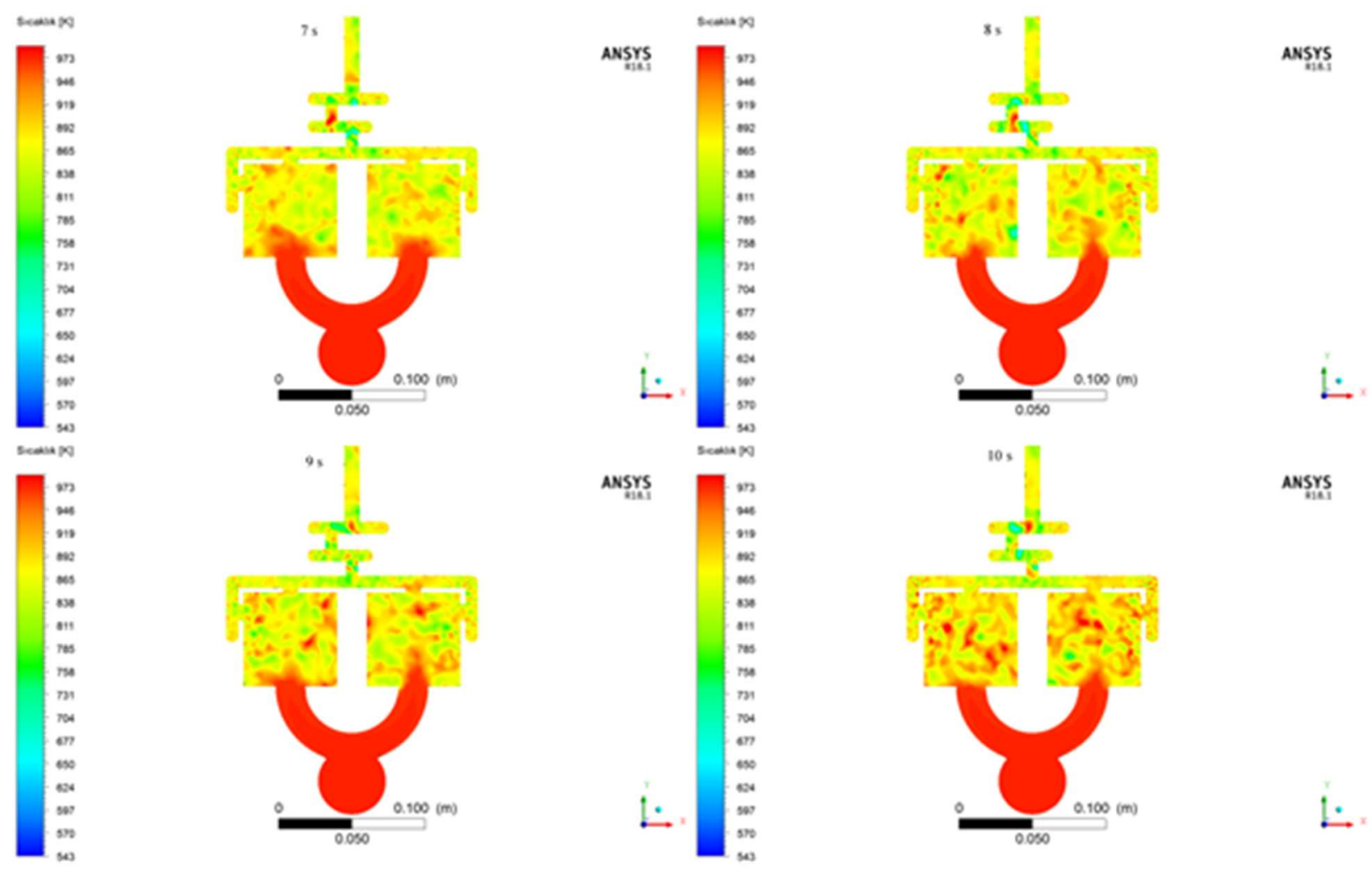

Şekil 6. Klasik soğutma kanalı için zamana bağlı sıcaklık konturları

Figure 6. Time-dependent temperature contours for the conventional cooling channel

Şekil 6' dan görüleceği gibi, kalıbın tam olarak soğutulmamasından dolayı ergiyik metalin sıcaklığında çok fazla bir değişim görülmemektedir. Ancak soğutma kanallarının olduğu bölgelerde soğutmanın etkisiyle sıcaklıklarda düşüşler olduğu gözlemlenmiştir. Soğutma işleminin başlamasıyla birlikte metal sıcaklığının zamana bağlı olarak, azaldığ 1,2 . s'den sonra kalıpta zamana bağlı olarak $811-643 \mathrm{~K}$ arasında değiştiği görülmektedir. Proses zamanının her 0.5 s'lik artışıyla, kalıptaki sıcaklık ortalama 20 ${ }^{\circ} \mathrm{C}$ düşmüştür.

Şekil 7'de klasik soğutma kanalı için dökümden sonraki ilk $0.5-10 \mathrm{~s}$ aralıklarındaki ergiyik metalin sıvı hacim oranının zamana bağlı olarak değişim konturlarının verilmiştir. 
Kan vd. / GUFBD / GUJS 12(1) (2022) 283-300
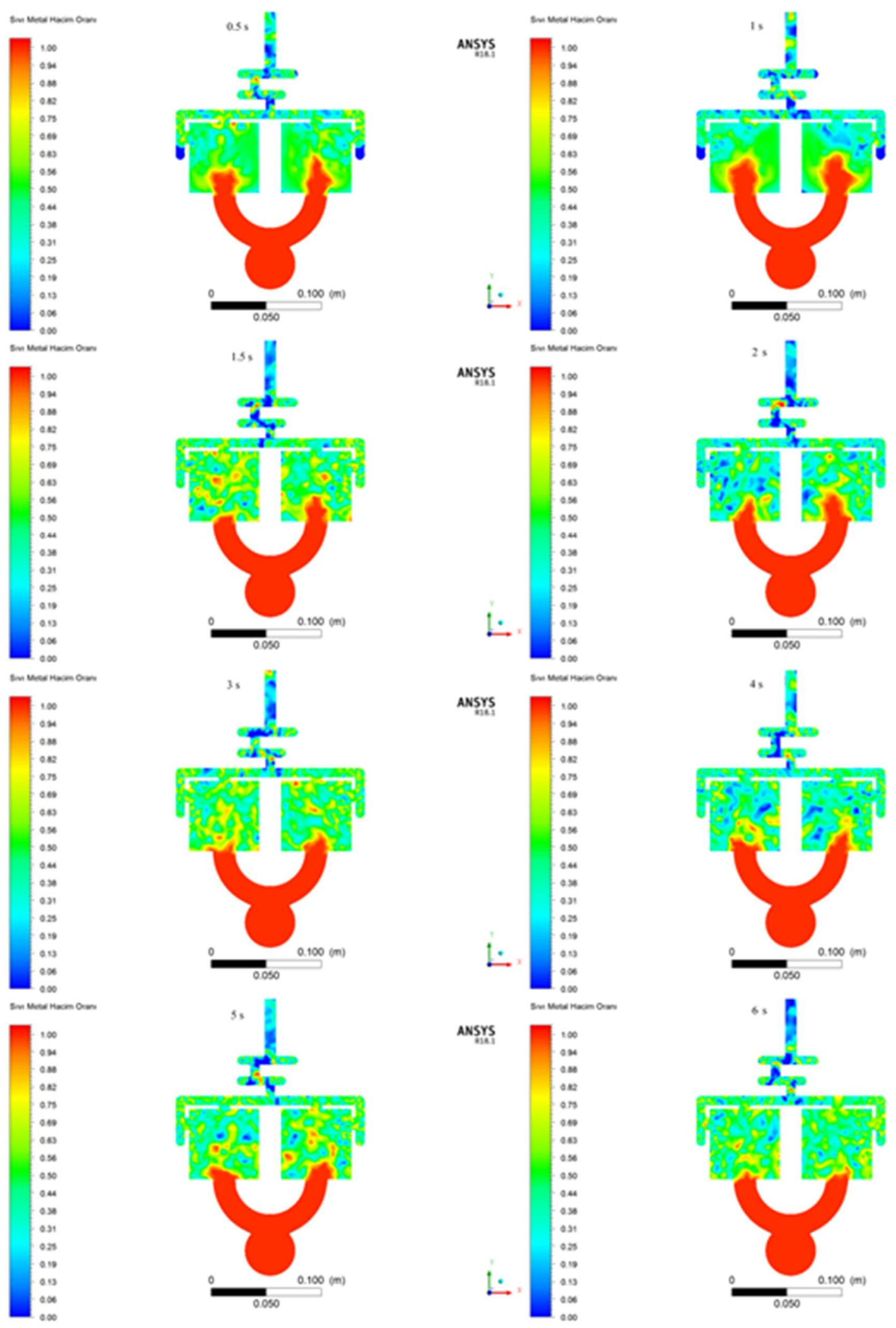

ANSYS
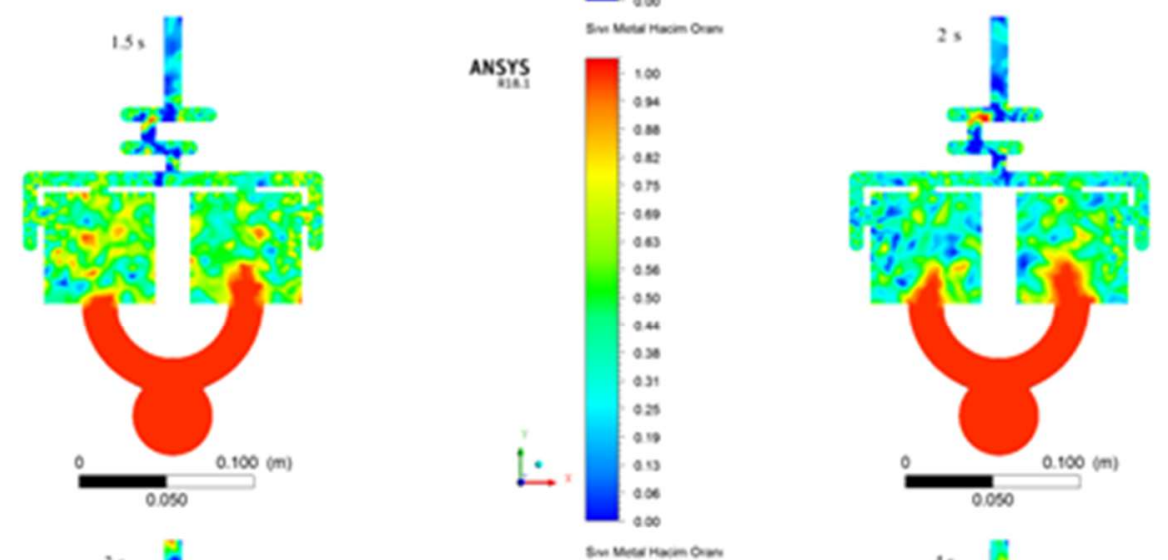

$\stackrel{1}{\circ}$
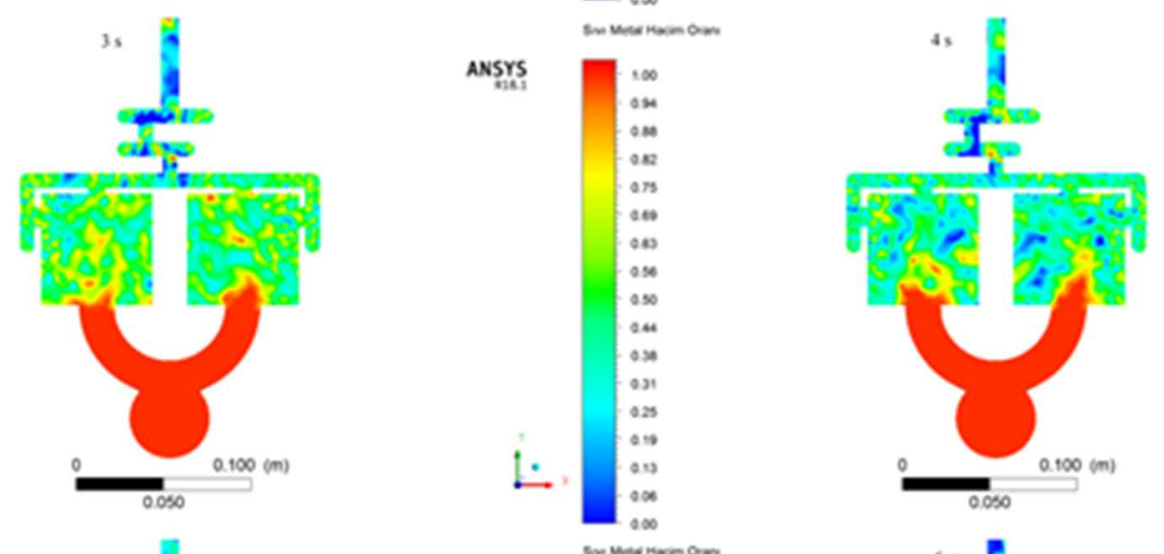

ansYs
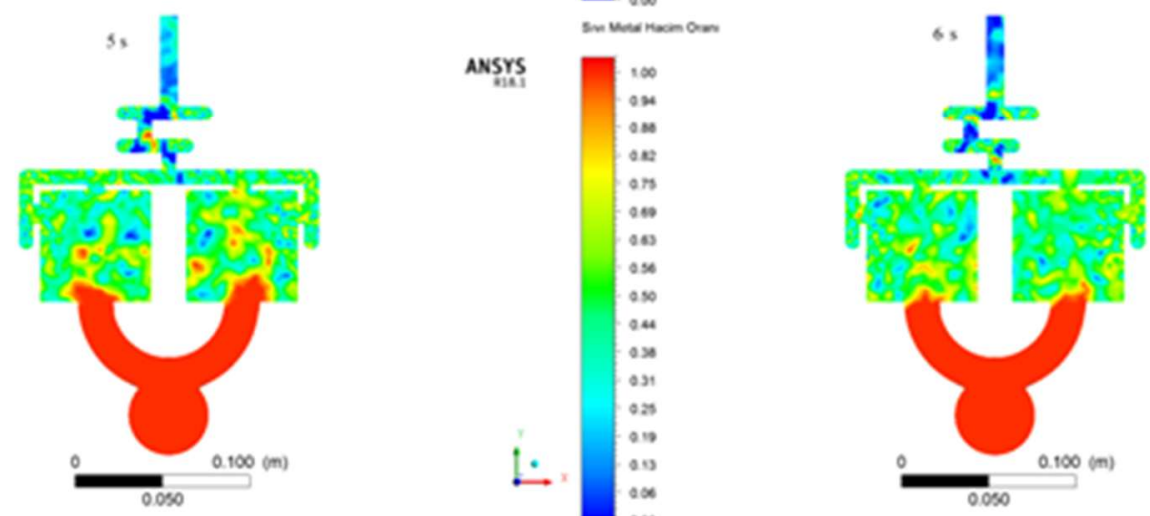

aNsYS
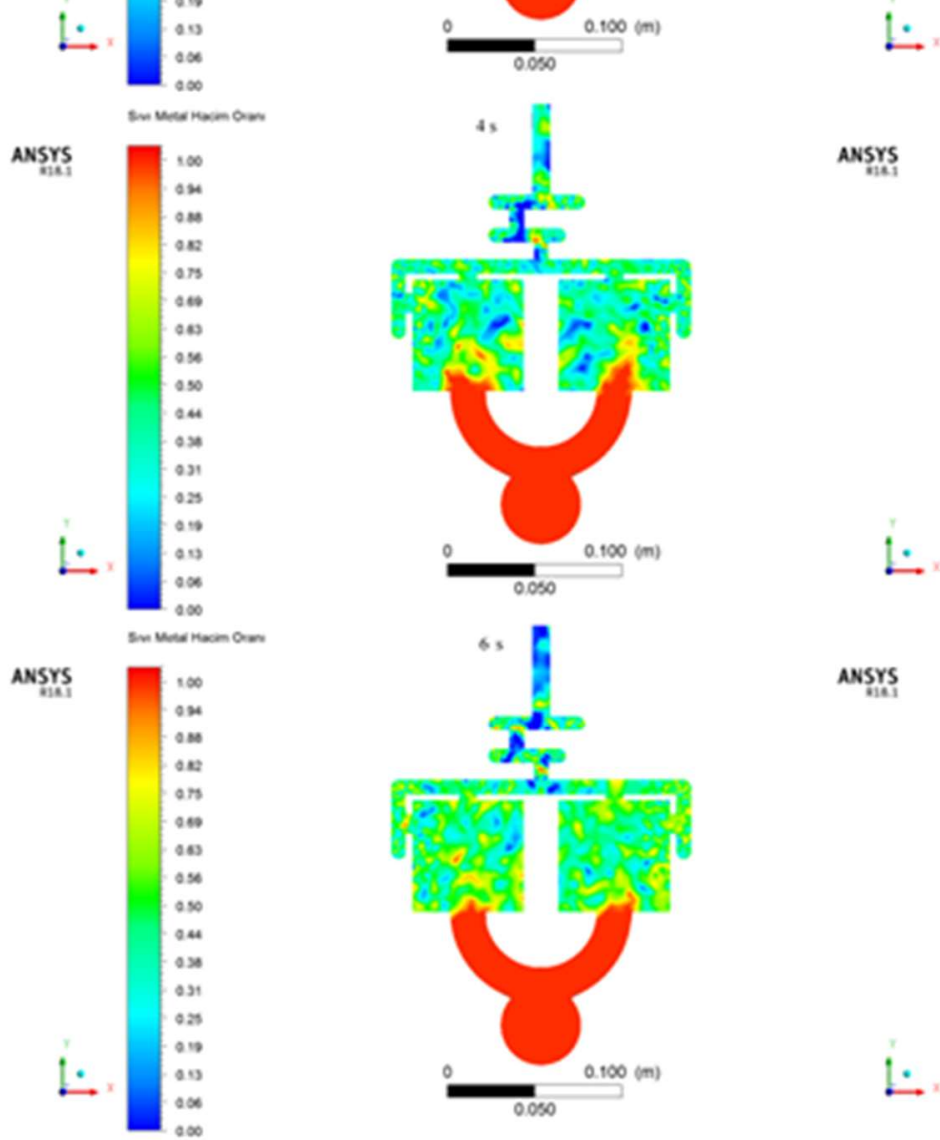

ANSYS
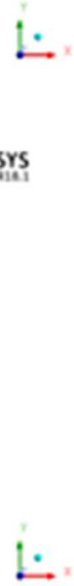

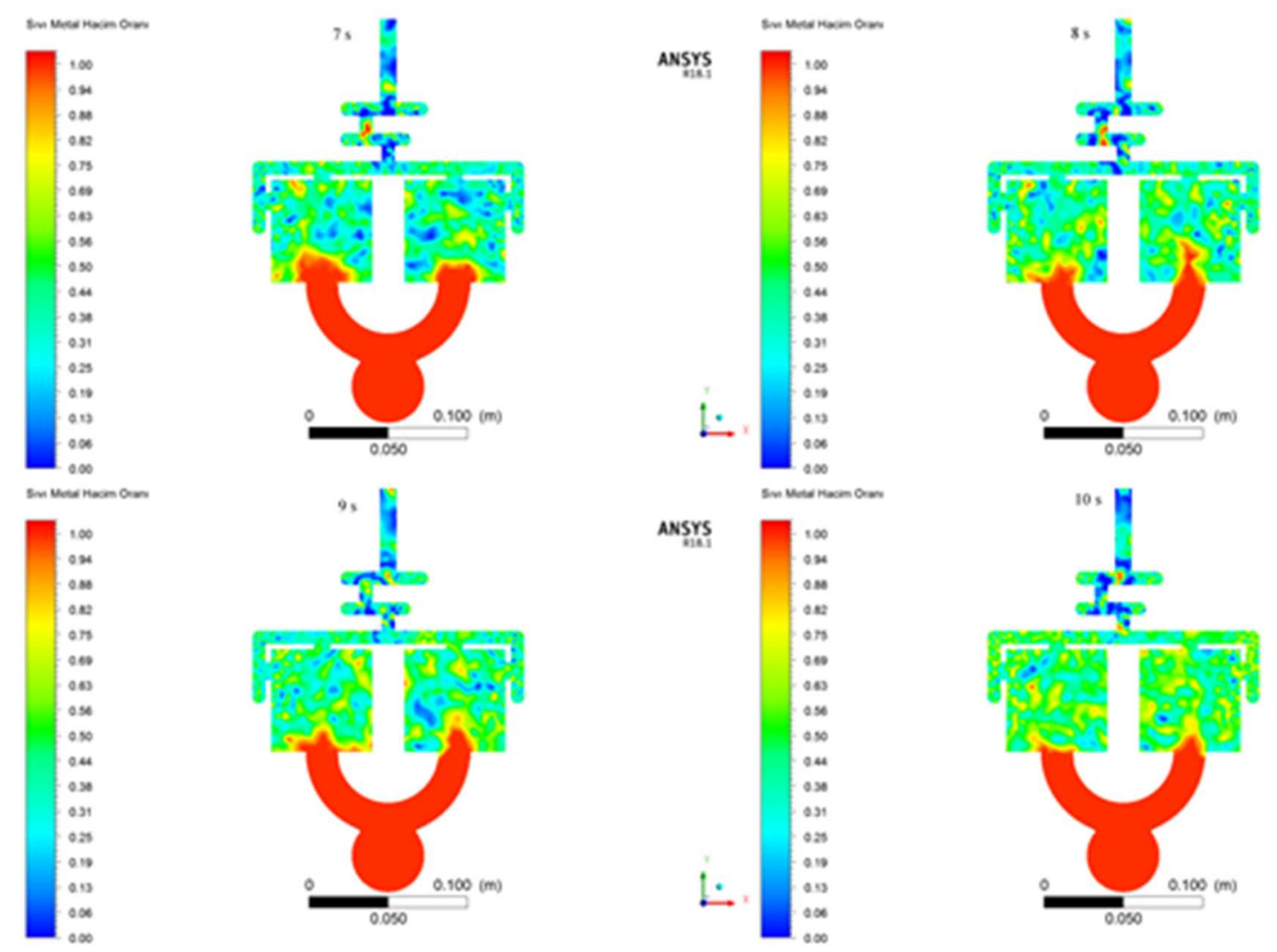

ANSYS

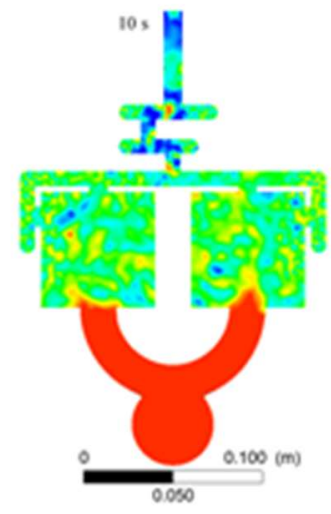

ANSYS

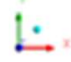

Şekil 7. Klasik soğutma kanalı için zamana bağlı sıv1- hacim oranı konturları

Figure 7. Time-dependent liquid-to-volume ratio contours for the conventional cooling channel

Şekil 7'de klasik soğutma kanalı için dökümden $0.5-10 \mathrm{~s}$ aralıklarına ait ergiyik metal boyunca sıvı hacim oranlarının zamana bağlı olarak değişimleri görülmektedir. Ergiyik metalin tamamen katılaşmasında değer 0 iken sıvı haldeki kısımlarda 1 değerini ifade etmektedir. 0 ile 1 aralığında ise katılaşmanın gerçekleşmediği kısımları göstermektedir. En hızlı soğuma ilk 2. s içerisinde gerçekleşirken sonraki zaman dilimlerinde soğuma hızı kısmen yavaşlamaktadır. Sıcaklık konturlarında olduğu gibi soğutma kanallarının geçtiği bölgelerde katılaşmanın olduğu gözlemlenmiştir. Buna göre, amaç hızlı soğumayı gerçekleştirmek ise, kalıp üzerinde uygun tasarlanmış soğutma kanallarının kullanılması gerektiği anlaşılmaktadır.

Şekil 8'de, özgün soğutma kanalı için dökümden sonraki ilk 0.5 - $10 \mathrm{~s}$ aralıklarındaki ergiyik metal boyunca sıcaklık dağılım konturlarının zamana bağlı olan değişimleri verilmiştir. 
Kan vd. / GUFBD / GUJS 12(1) (2022) 283-300
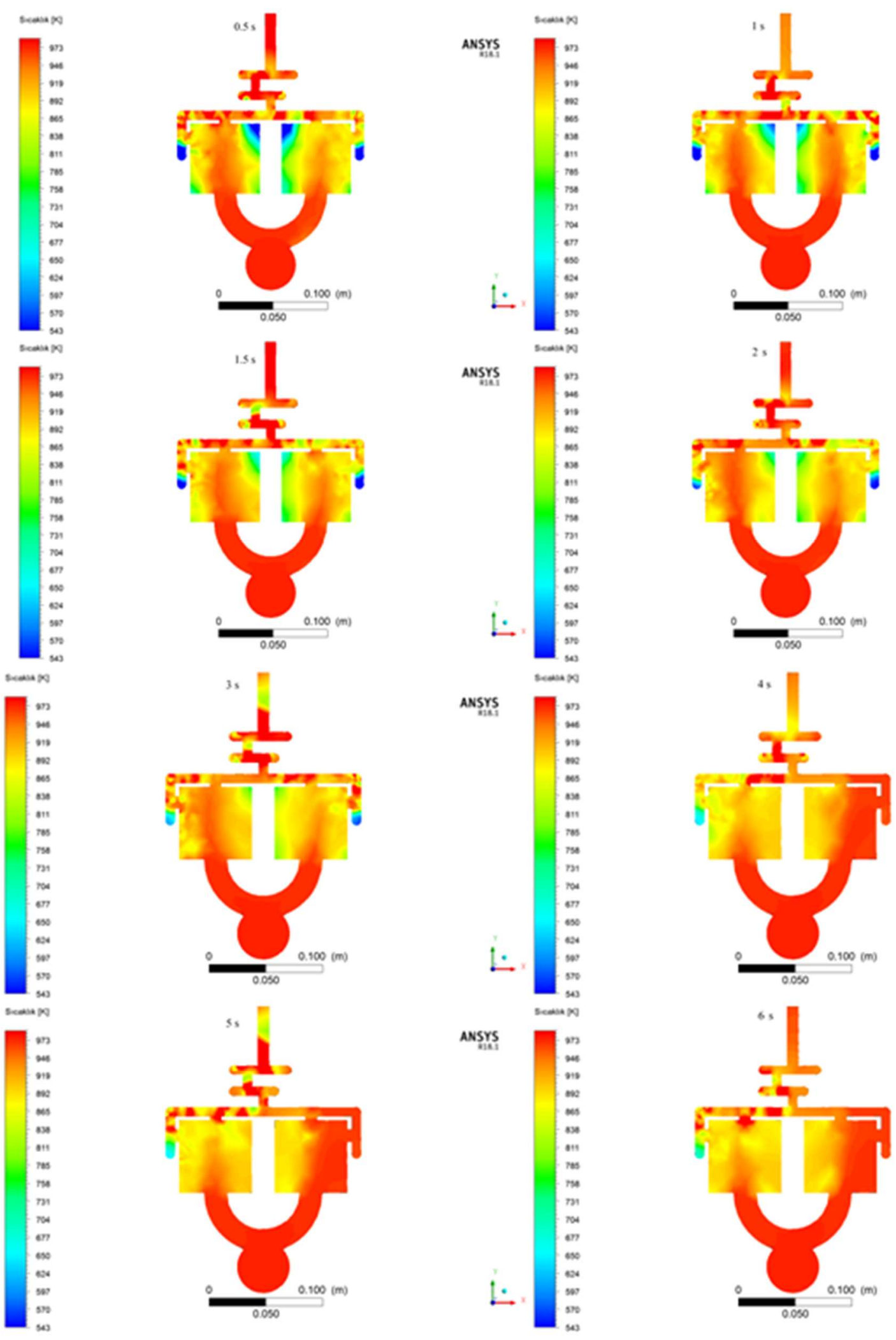

ANSYS
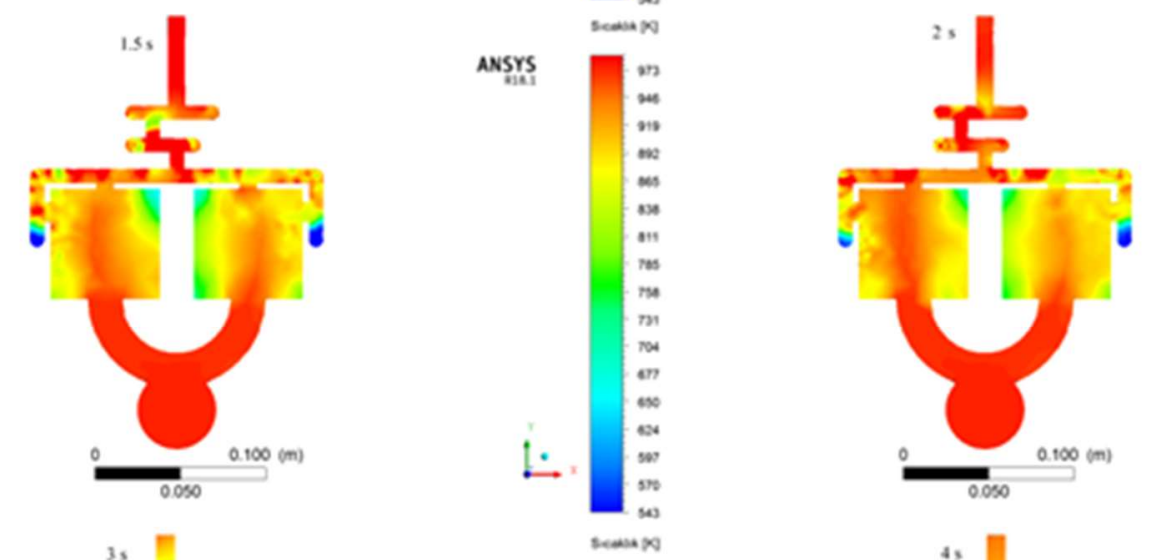

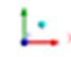
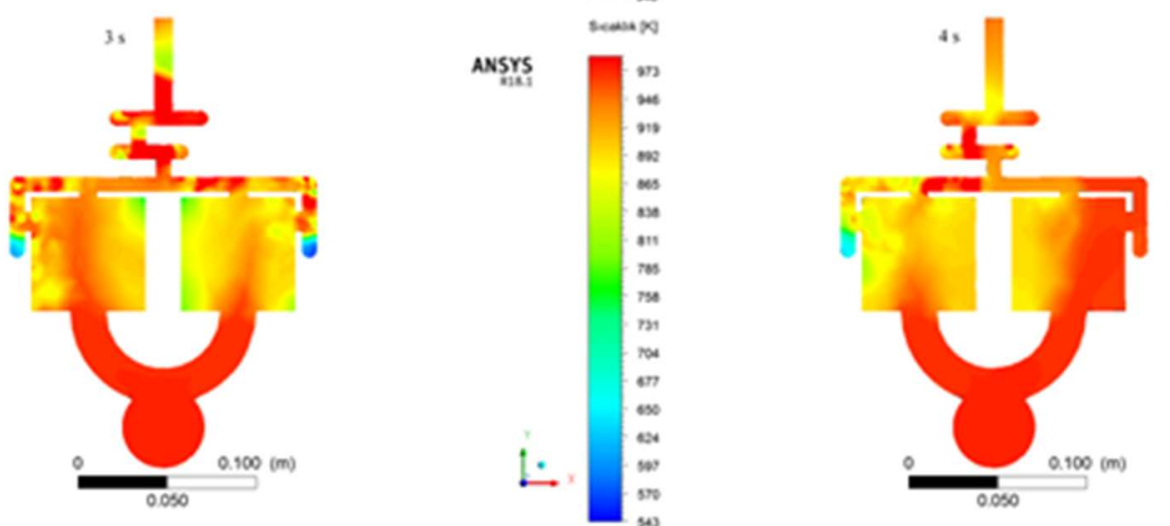

ANSYS
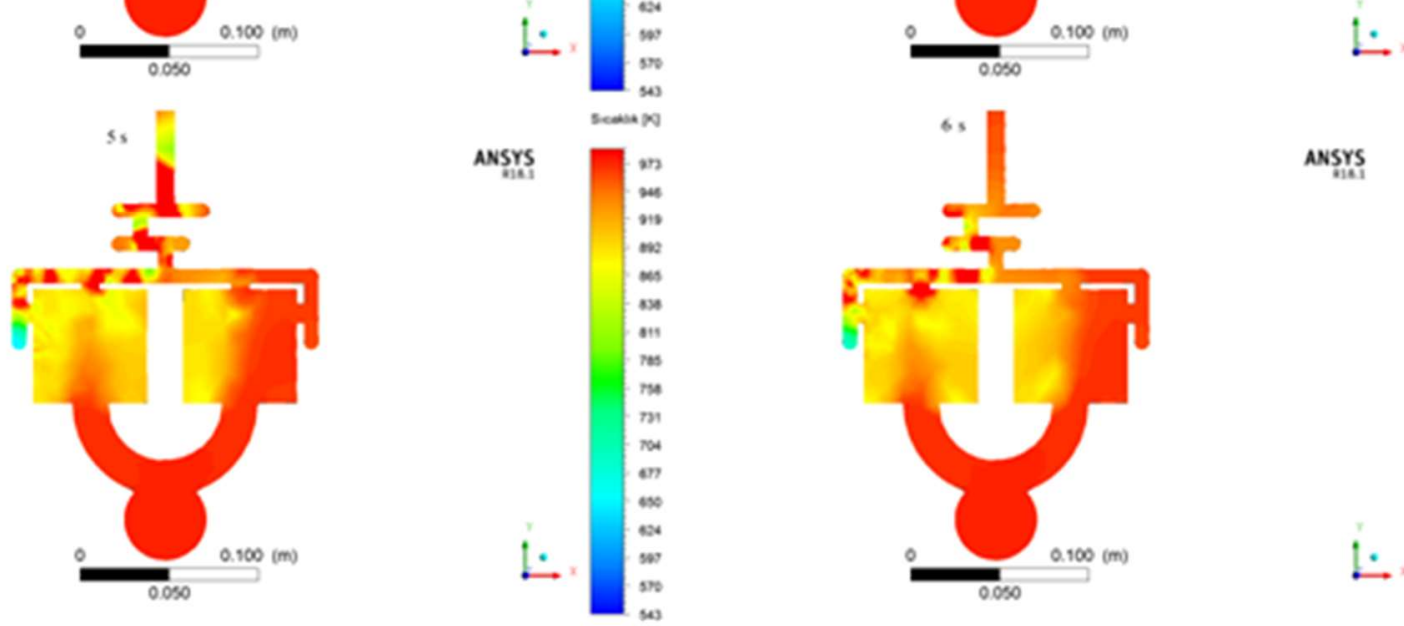

ANSYYS

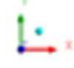



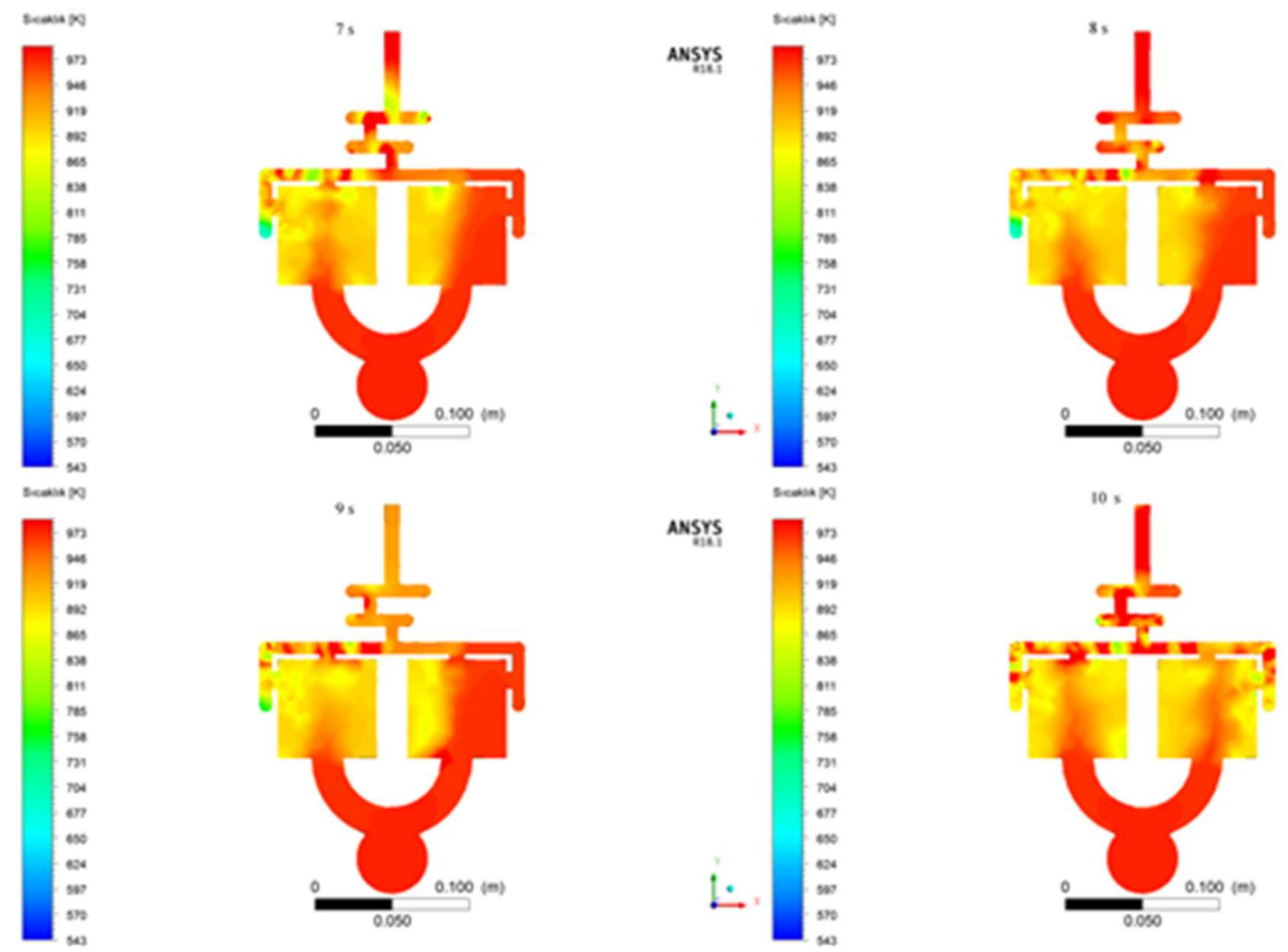

ANSYS
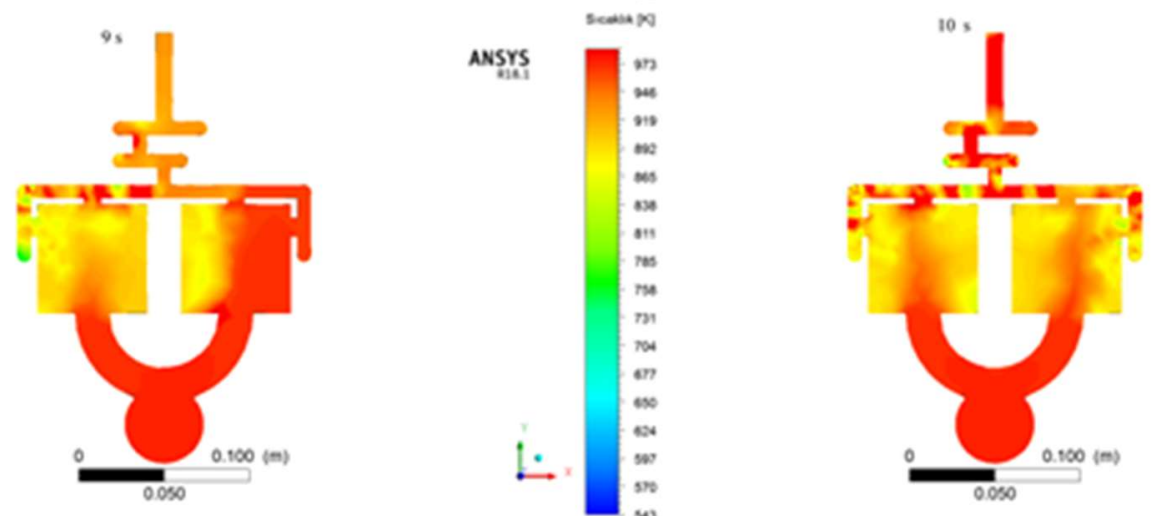

ansys

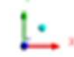

Şekil 8. Özgün soğutma kanalı için zamana bağl1 sıcaklık konturları

Figure 8. Time-dependent temperature contours for the unique cooling channel

Şekil 8' den görüleceği gibi, özgün soğutma kanallı kalıpta klasik soğutma kanallı kalıba göre sıcaklık farklıkları dikkati çekmektedir. Zamana bağlı olarak, soğutmanın yapılmasıyla birlikte sıcaklığın azalmaya başladığı ve homojen dağılım olduğu görülmektedir. Soğutma işleminin başlamasıyla birlikte metal sıcaklığının zamana bağlı olarak, azaldığı, 2. s'den sonra kalıpta zamana bağlı olarak
763- $551 \mathrm{~K}$ arasında değiștiği görülmektedir. Proses zamanının her 0.5 s'lik artışıyla, kalıptaki sicaklık ortalama $30{ }^{\circ} \mathrm{C}$ düşmüştür.

Şekil 9'da özgün soğutma kanalı için dökümden sonraki ilk $0.5-10 \mathrm{~s}$ aralıklarındaki ergiyik metalin sıvı hacim oranının zamana bağlı olarak değişim konturlarının verilmiştir. 
Kan vd. / GUFBD / GUJS 12(1) (2022) 283-300
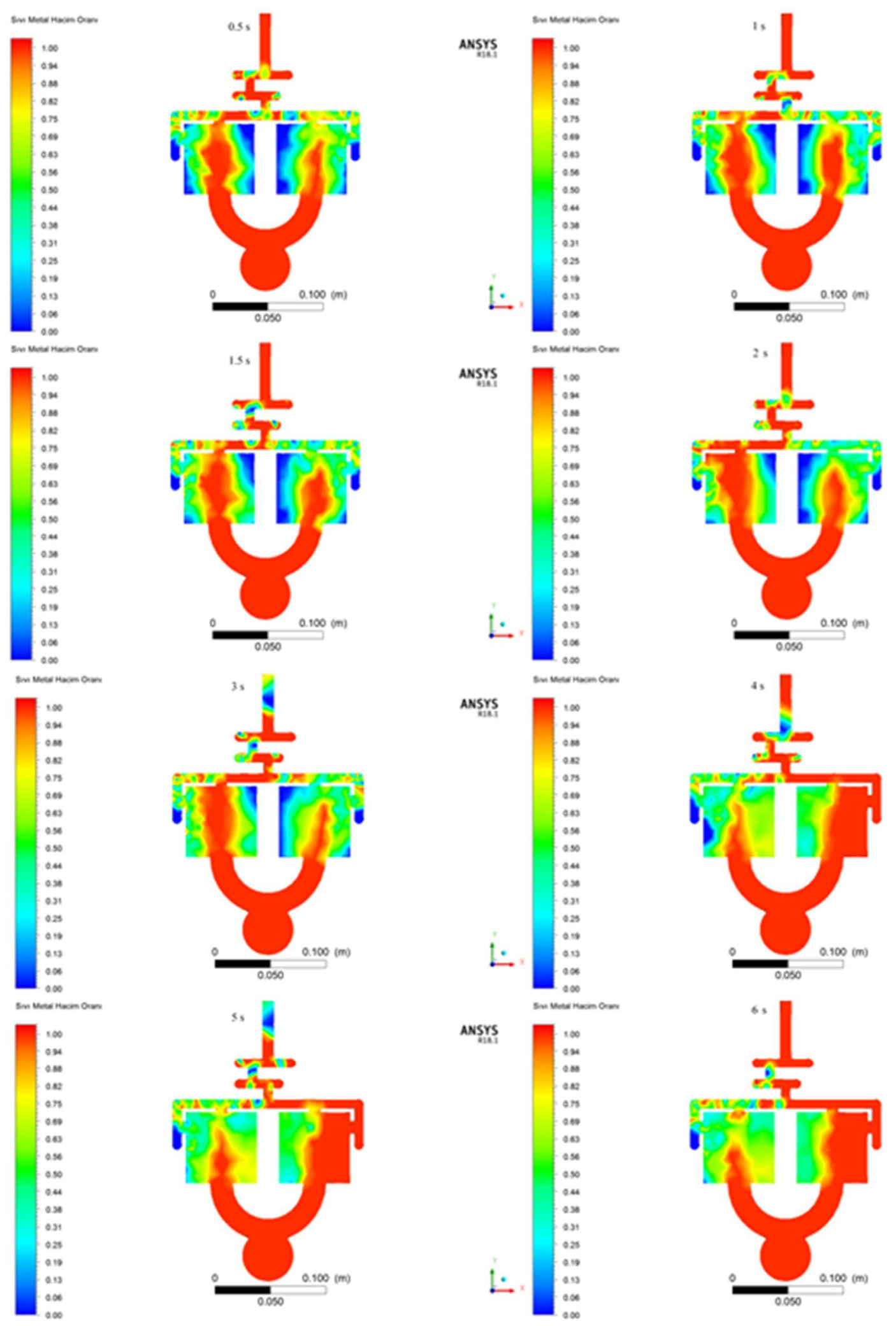

ANSYYS
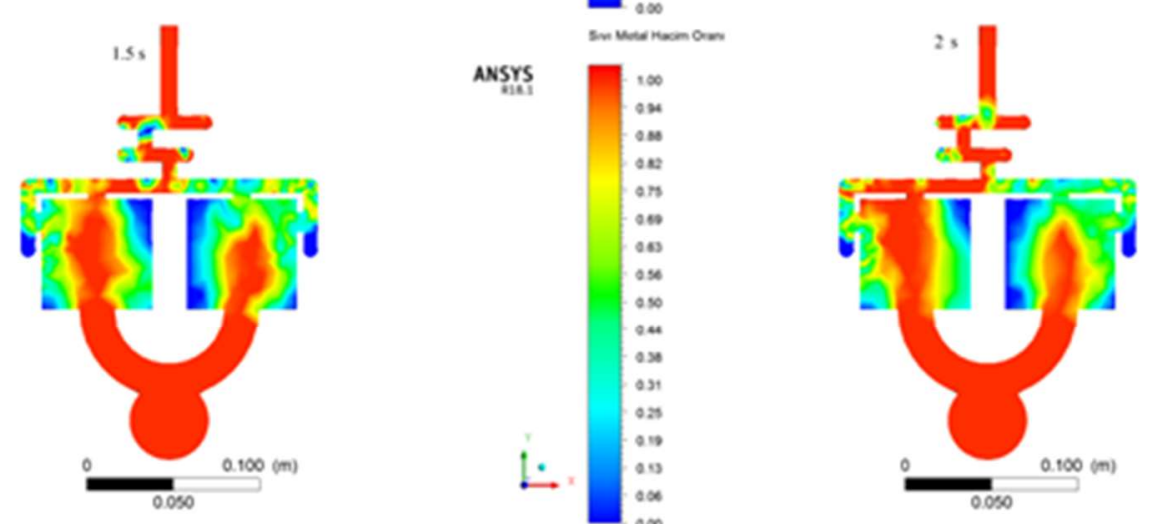

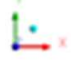
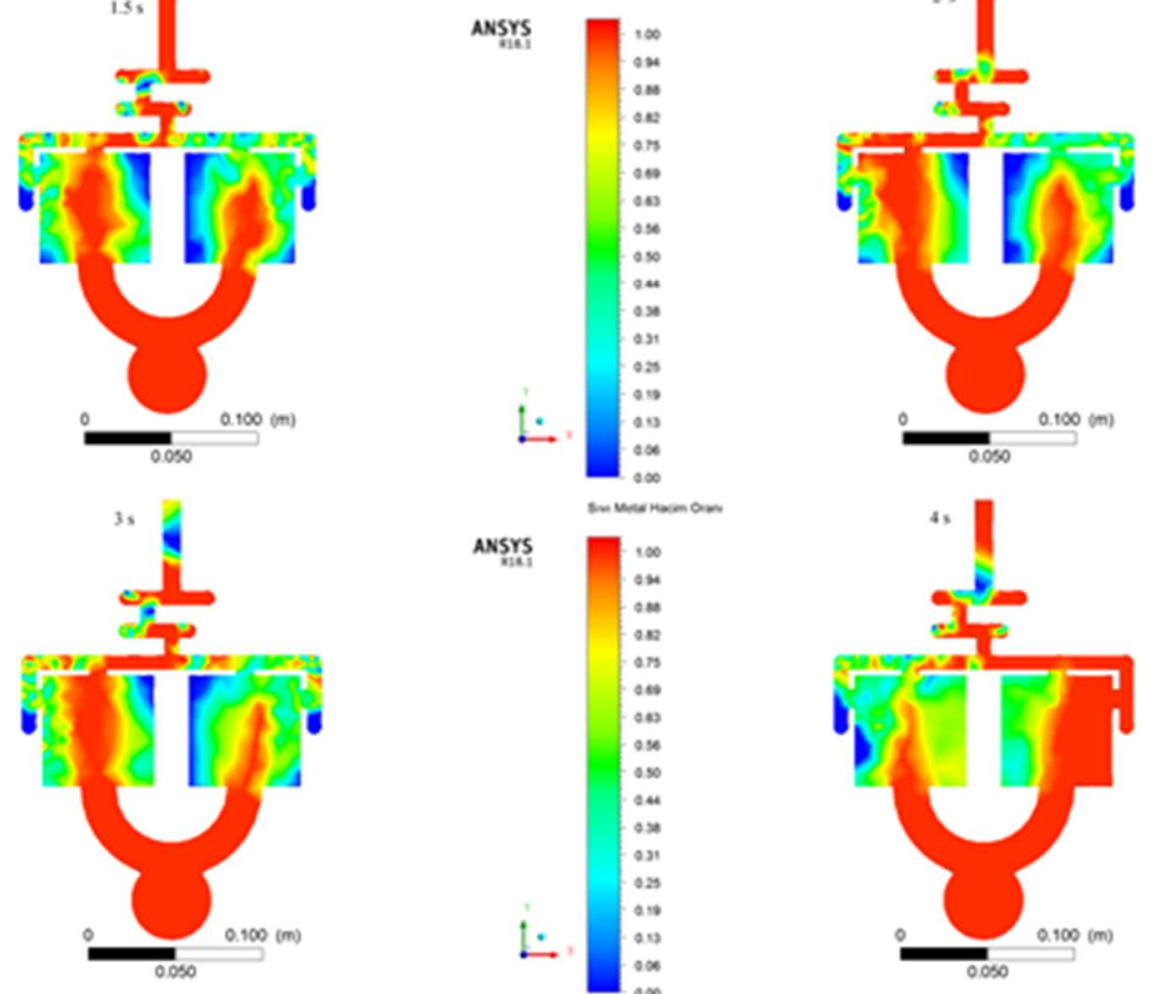

$\stackrel{1}{\circ}$
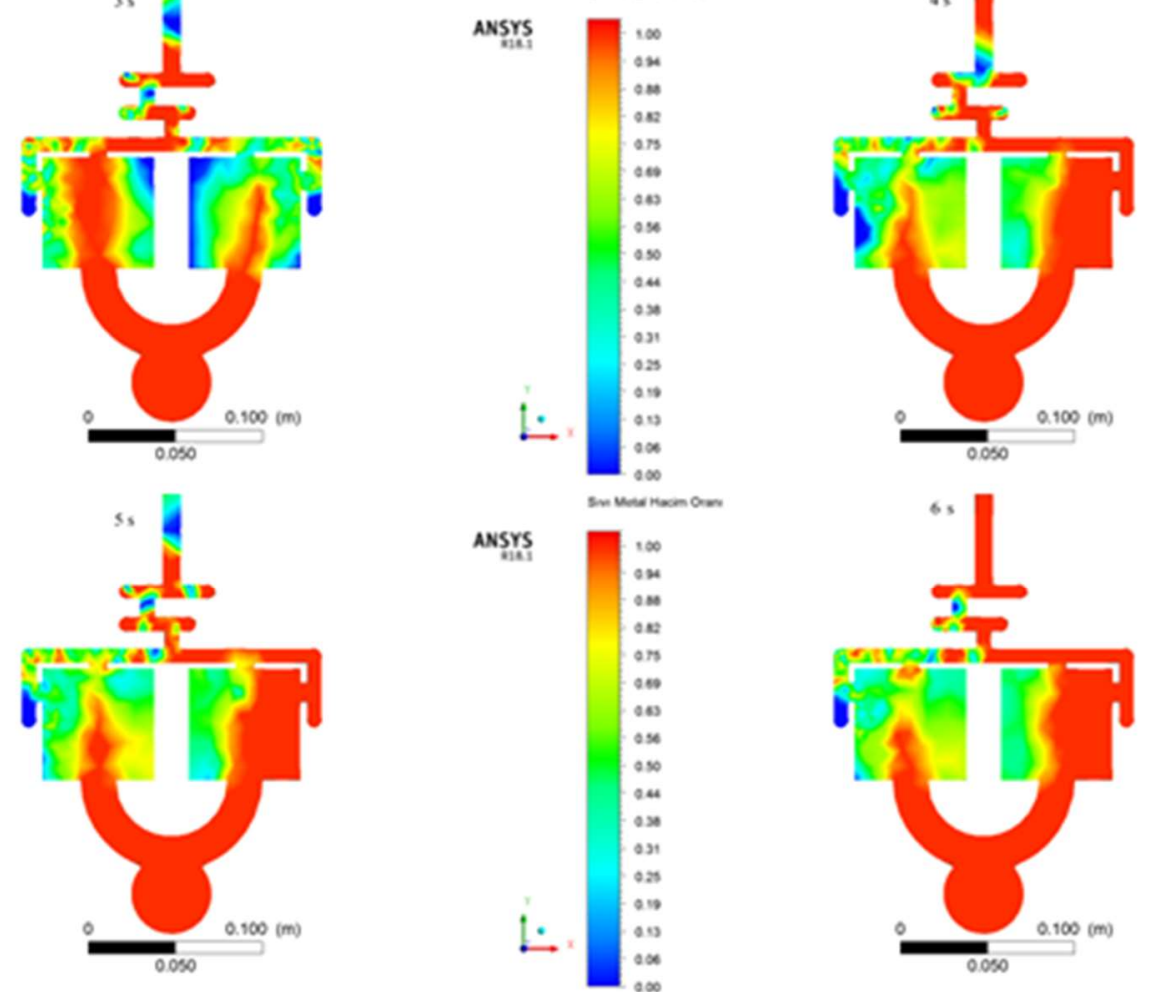

ansys

ANSYS

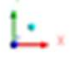

anşrs

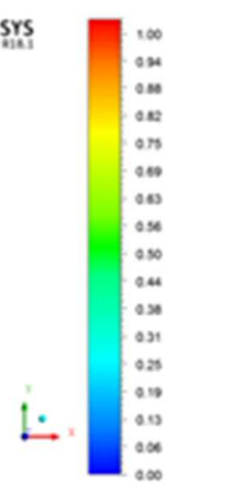

ansys

$\vdots$ 

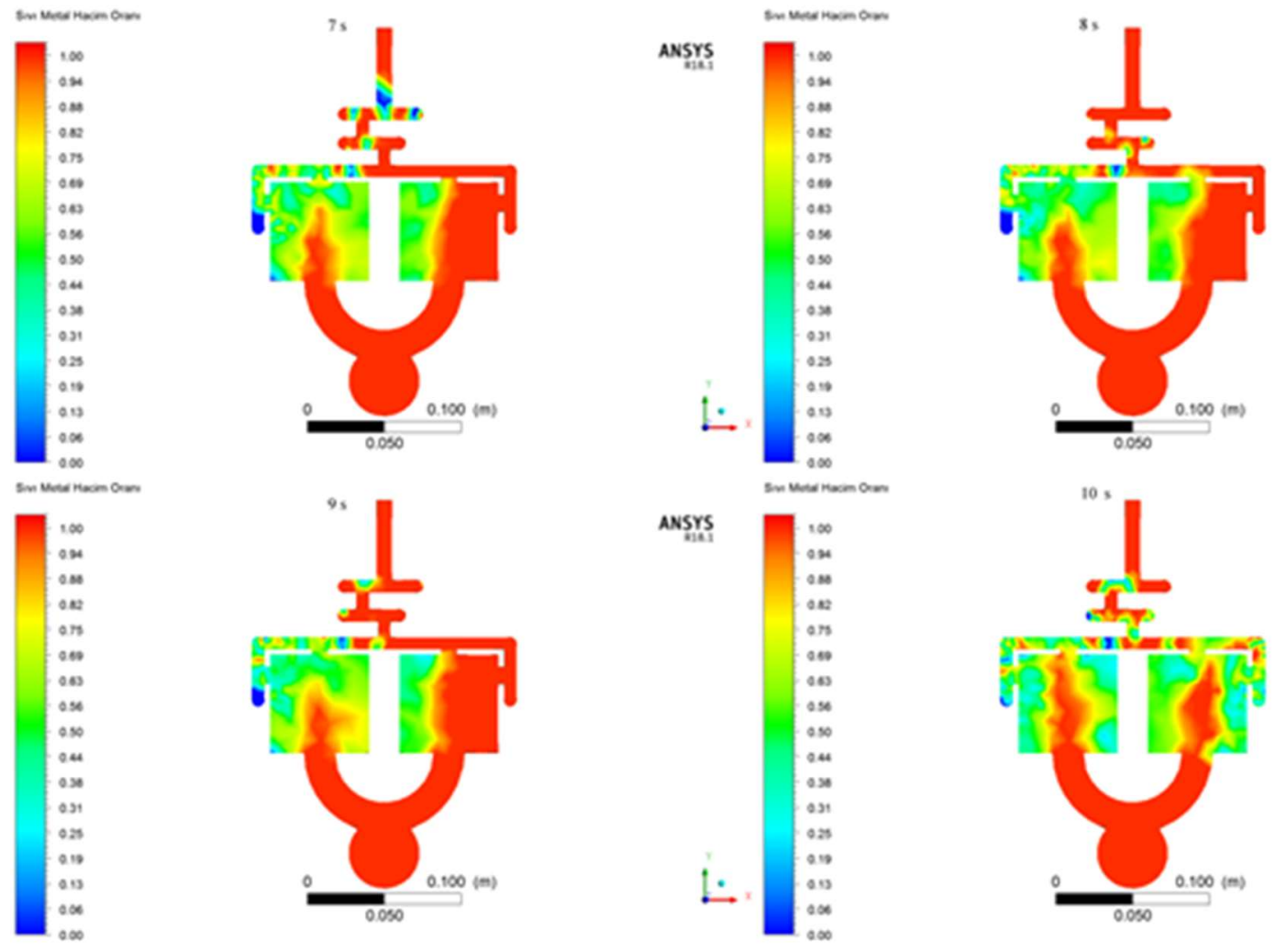

ANSYS
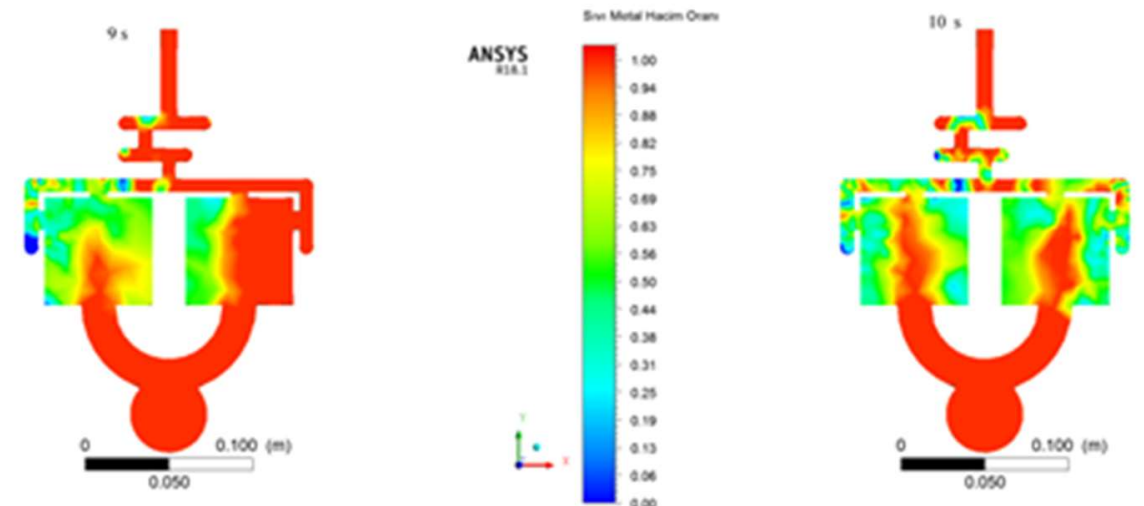

\llcorner

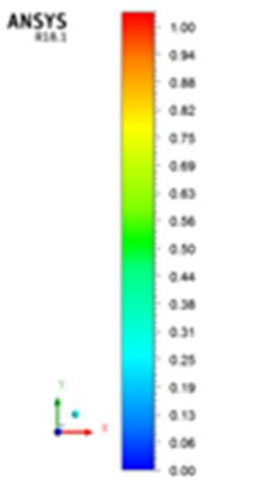

ANSYS

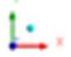

Şekil 9. Özgün soğutma kanalı için zamana bağlı sıv1- hacim oranı konturları

Figure 9. Time-dependent liquid-to-volume ratio contours for a unique cooling channel

Şekil 9' dan görüleceği gibi, özgün soğutma kanallı kalıpta klasik soğutma kanallı kalıba göre katılaşma hızı dikkati çekmektedir. Zamana bağlı olarak, soğutmanın yapılmasıyla birlikte sıcaklığın azalmaya başladığı ve katılaşmanın daha hızlı olduğu görülmektedir. Soğutma kanallarının etkisiyle en hızlı soğuma ilk 1.5. s içerisinde gerçekleşirken sonraki zaman dilimlerinde soğuma hızı kısmen yavaşlamaktadır. Böylece kalıbı soğutma için harcanan zamanda azalma olduğu gözlemlenmiştir.

Şekil 10'da verilen grafikte klasik soğutma kanallı kalıp sıcaklık dağılımlarının farklı mesafelerdeki karşılaştırılması verilmiştir. Buradaki $1 \mathrm{~mm}, 3 \mathrm{~mm}$, $5 \mathrm{~mm}$ mesafeler biscuit kısminda ergiyik metalin kalıpla temas ettiği noktadan itibaren kalıba doğru olan mesafelerdir.

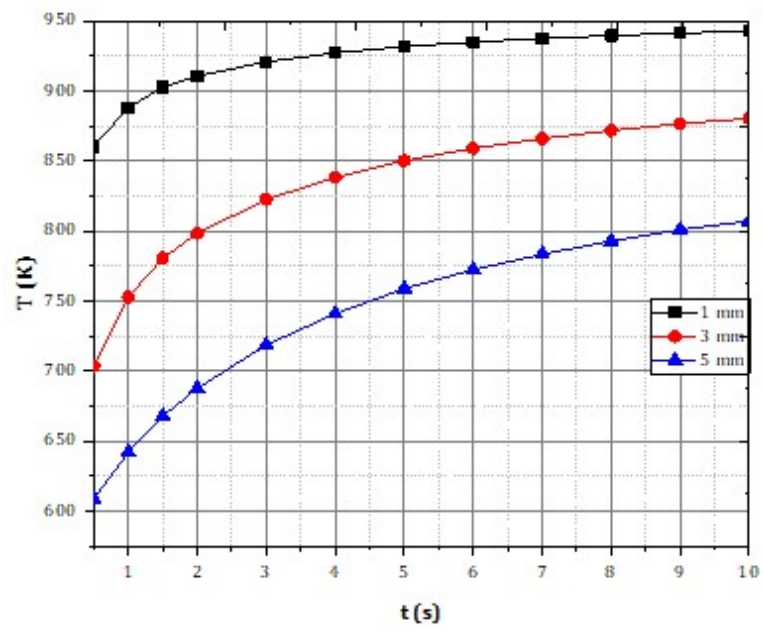

Şekil 10. Klasik soğutma kanallı kalıbın farklı mesafelerdeki sıcaklık dağılımlarının zamana bağlı karşı1laştırılması

Figure 10. Time-dependent comparison of the temperature distributions of the conventional cooling channel mold at different distances 


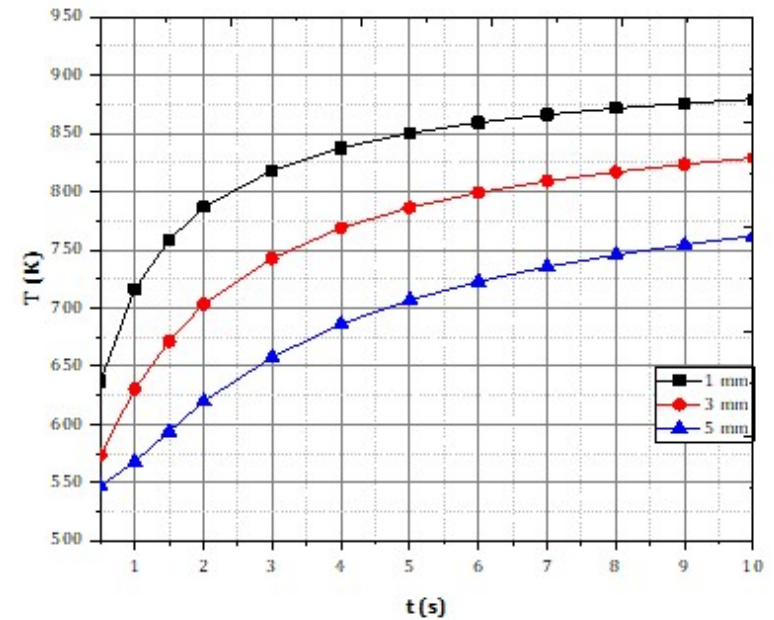

Şekil 11. Özgün soğutma kanallı kalıbın farklı mesafelerdeki sıcaklık dağılımlarının zamana bağlı karşılaştırılması

Figure 11. Time-dependent comparison of temperature distributions at different distances of a unique cooling channel die

Şekil 10'da, klasik soğutma kanallı kalıpta biscuit kısmında ergiyik metalin kalıpla temas ettiği $1 \mathrm{~mm}$ mesafedeki noktada sicaklıklar 943-857 K arasinda, $3 \mathrm{~mm}$ mesafedeki noktada 871-701 K arasında ve son olarak $5 \mathrm{~mm}$ mesafedeki noktada ise 803-611 $\mathrm{K}$ arasında değișiklik göstermektedir. Şekil 11'den de görüldüğü üzere; özgün soğutma kanallı kalıpta biscuit kısmında ergiyik metalin kalıpla temas ettiği $1 \mathrm{~mm}$ mesafedeki noktada sicaklıklar 888-632 $\mathrm{K}$ arasında, $3 \mathrm{~mm}$ mesafedeki noktada 727-575 K arasinda ve son olarak $5 \mathrm{~mm}$ mesafedeki noktada ise 759-548 $\mathrm{K}$ arasinda değişiklik göstermektedir. Şekil 10 ve Şekil 11'den de görülebileceği gibi; kalıpların farklı mesafelerdeki kalıp sicaklıkları arasında farklılıklar olduğu gözlemlenmiştir. Soğutmanın etkisiyle ve arada meydana gelen 1s1 transferinin daha yüksek olmasiyla özgün soğutma kanallı kalıpta sıcaklıkların daha düşük olduğu görülmektedir. Özgün soğutma kanallı kalıpta klasik soğutma kanallı kalıba göre 1.33 kat daha iyi sıcaklık düşüşü gerçekleşmiştir. Burada daha homojen bir soğutmanın gerçekleştiği katılaşmanın daha hızlı olduğu düşünülmektedir. Ayrıca ergiyik metalden uzaklaştıkça kalıbın sıcaklığı düşmektedir. Klasik soğutma kanallı kalıpta sicakliklar

Şekil 12'de analizlerden elde edilen veriler doğrultusunda hesaplanan zamana bağlı arayüzey 1sı transfer katsayıları verilmiştir.

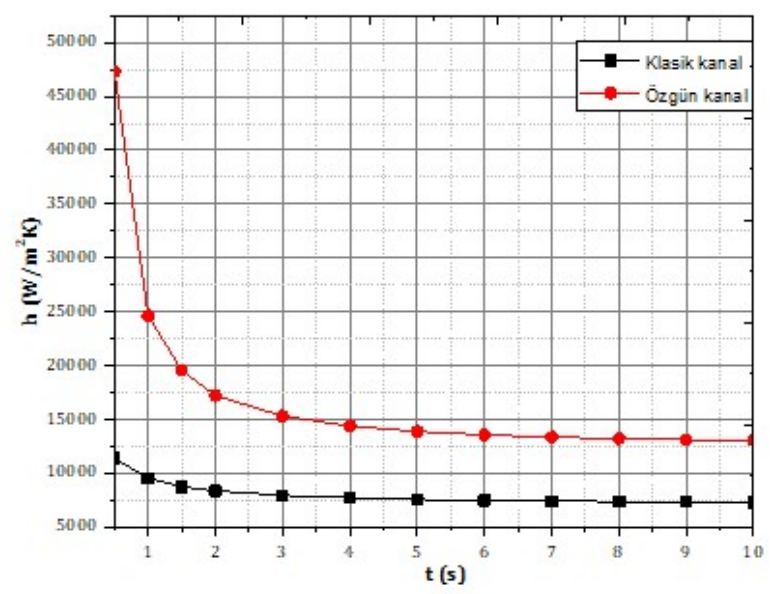

Şekil 12. Zamana bağlı arayüzey 1 sı transfer katsayılarının karșılaştırılması

Figure 12. Comparison of time dependent interfacial heat transfer coefficients

Şekil 12'de, hesaplanan arayüzey 1S1 transfer katsayılarının zamanla azaldığı görülmektedir. Grafikten de görüleceği üzerine, özgün soğutma kanallı kalıpta arayüzey 1sı transfer katsayısının daha iyi olduğu görülmektedir. 0.5-10 s aralığ 1 dikkate alındığında; özgün soğutma kanallı kalıpta ortalama arayüzey 1s1 transfer katsayıs1 18210 $\mathrm{W} / \mathrm{m}^{2} \mathrm{~K}$ olduğu ve klasik soğutma kanallı kalıpta ise $8164.4 \mathrm{~W} / \mathrm{m}^{2} \mathrm{~K}$ olarak hesaplanmıştır. Özgün soğutma kanallı kalıpta klasik soğutma kanallı kalıba kıyasla 2.23 kat daha iyi 1sı transfer katsayıs1 olduğu hesaplanmıştır.

\section{Tartışma ve sonuçlar}

\section{Discussion and conclusions}

Yapılan bu çalışma kapsamında, basınçlı döküm ile H13 çeliğinden yapılacak bir kalıba, A16061 alaşımından yapılan döküm işlemi, 3D-CAD programı yardımıyla modellenerek katılaşma süresi, sıcaklık dağılımları ve AITK'sı sonlu elemanlar metoduyla incelenmiștir. Öncelikli olarak klasik soğutma kanalı kalıp tasarımı yapılmıştır. Daha sonra özgün soğutma kanallı kalıp çekirdeği tasarlanmıştır. $\mathrm{Bu}$ tasarımlar üzerinde, Ansys-Fluent programı kullanılarak nümerik analiz çalışmaları yapılmıştır. AnsysFluent programı kullanılarak yapılan nümerik hesaplamalarda, kalıp içerisinde sirküle edecek soğutucu akışkanın kanal içindeki akış ve 1sıl davranışları gözlemlemek amacıyla HAD analizlerinden yararlanılmıştır.

Klasik soğutma kanallı kalıpta, soğutma işleminin başlamasıyla birlikte metal sicaklığının zamana bağlı olarak, azaldığı, 2. s'den sonra kalıpta zamana bağlı olarak 811- $643 \mathrm{~K}$ arasında değiştiği 
görülmektedir. Proses zamanının her 0.5 s'lik artışıla, kalıptaki sıcaklık ortalama $20 \quad{ }^{\circ} \mathrm{C}$ düşmüştür. Özgün soğutma kanallı kalıpta ise, soğutma işleminin başlamasıyla birlikte metal sıcaklığının zamana bağlı olarak, azaldığı, 2. s'den sonra kalıpta zamana bağlı olarak $763-551 \mathrm{~K}$ arasında değiştiği görülmektedir. Proses zamanının her 0.5 s'lik artışıla, kalıptaki sıcaklık ortalama 30 ${ }^{\circ} \mathrm{C}$ düşmüștür.

Klasik soğutma kanallı kalıpta biscuit kısmında ergiyik metalin kalıpla temas ettiği $1 \mathrm{~mm}$ mesafedeki noktada sicaklıklar 943-857 K arasında, $3 \mathrm{~mm}$ mesafedeki noktada 871-701 K arasında ve son olarak $5 \mathrm{~mm}$ mesafedeki noktada ise 803-611 $\mathrm{K}$ arasında değişiklik göstermektedir. Özgün soğutma kanallı kalıpta biscuit kısmında ergiyik metalin kalıpla temas ettiği $1 \mathrm{~mm}$ mesafedeki noktada sicaklıklar 888-632 K arasında, $3 \mathrm{~mm}$ mesafedeki noktada 727-575 K arasında ve son olarak $5 \mathrm{~mm}$ mesafedeki noktada ise 759-548 $\mathrm{K}$ arasında değişiklik göstermektedir. Kalıpların farklı mesafelerdeki kalıp sıcaklıkları arasında farklılıklar olduğu gözlemlenmiştir. Soğutmanın etkisiyle ve arada meydana gelen 1S1 transferinin daha yüksek olmasiyla özgün soğutma kanallı kalıpta sıcaklıkların daha düşük olduğu görülmektedir. Özgün soğutma kanallı kalıpta klasik soğutma kanallı kalıba göre 1.33 kat daha iyi sıcaklık düşüşü gerçekleşmiştir.

0.5-10 s aralığı dikkate alındığında; özgün soğutma kanallı kalıpta ortalama arayüzey 1S1 transfer katsayıs $18210 \mathrm{~W} / \mathrm{m}^{2} \mathrm{~K}$ olduğu ve klasik soğutma kanallı kalıpta ise $8164.4 \quad \mathrm{~W} / \mathrm{m}^{2} \mathrm{~K}$ olarak hesaplanmıştır. Özgün soğutma kanallı kalıpta klasik soğutma kanallı kalıba kıyasla 2.23 kat daha iyi 1sı transfer katsayısı olduğu hesaplanmıştır.

$\mathrm{Bu}$ çalışma sayesinde özgün soğutma kanallı kalıp tasarımı, imalatı ve optimum çalışma şartlarının belirlenmesi konusunda ileride yapılacak uygulamalara katkı sağlayacaktır. $\mathrm{Bu}$ çalışmadaki tasarımlar yapılacak olan özgün soğutma kanallı kalıpların yolluk, itici ve soğutma sistemlerinin iyileştirilmesinde yarar sağlayacaktır. Yapılan tasarımların ve analizlerin özgün soğutma kanallı kalıp soğutma performansına katkısı olacaktır. Analizlerin, özgün soğutma kanallı kalıbın imalata geçilmeden önce gerekli revizelerin yapılmasına ve imalat için maliyetin azalmasına yardımcı olması beklenmektedir.

\section{Yazar katkısı}

Author contribution

Bütün yazarlar araştırmaya eşit oranda katkıda bulunmuşlardır.

\section{Etik beyanı}

Declaration of ethical code

$\mathrm{Bu}$ çalışmada, "Yükseköğretim Kurumları Bilimsel Araştırma ve Yayın Etiği Yönergesi" kapsamında uyulması gerekli tüm kurallara uyulduğunu, bahsi geçen yönergenin "Bilimsel Araştırma ve Yayın Etiğine Aykırı Eylemler" başlığ1 altında belirtilen eylemlerden hiçbirinin gerçekleştirilmediğini taahhüt ederiz."

\section{Çıkar çatışması beyanı}

Conflicts of interest

$\mathrm{Bu}$ çalışmadaki yazarların herhangi bir çıkar çatışması bulunmamaktdır.

\section{Kaynaklar \\ References}

Akar N., Sahin H.M., Yalçın N. \& Kocatepe K. (2008). Experimental study on the effect of liquid metal superheat and casting height on interfacial heat transfer coefficient. Experimental Heat Transfer, 21(1),83-98. https://doi.org/10.1080/08916150701647785

Akar N., Boran K. \& Hozikliğil B. (2013). Kalıp sıcaklığının döküm parça-kalıp arayüzey 1sı transfer katsayıs1 üzerine etkisi. Gazi Üniversitesi Mühendislik Mimarlı Fakültesi Dergisi, 28(2), 275-282.

Arunkumar, S., Rao, K. S., \& Kumar, T. P. (2008). Spatial variation of heat flux at the metal-mold interface due to mold filling effects in gravity die-casting. International Journal of Heat and Mass Transfer, 51(11-12), 2676-2685. https://doi.org/10.1016/j.ijheatmasstransfer.200 7.10 .020

Bouchard D., Leboeuf S., Nadeau J.P., Guthrie I.L.R. \& Mihaiela I. (2009). Dynamic wetting and heat transfer at the initiation of aluminum solidification on copper substrates. Journal of Materials Science, 44(8), 1923-1933. https://doi.org/10.1007/s10853-008-2888-3

Chen, Z.W. (2003). Skin solidification during high pressure die casting of $\mathrm{Al}-11 \mathrm{Si}-2 \mathrm{Cu}-1 \mathrm{Fe}$ alloy. Materials Science and Engineering: A, 348(1-2), 145-153. $\quad$ https://doi.org/10.1016/S09215093(02)00747-5 
Christy T.V., Murugan N. \& Kumar S. (2010). A comparative study on the microstructures and mechanical properties of $\mathrm{Al} 6061$ alloy and the MMC Al 6061/TiB $2 / 12 p$. Journal of Minerals\&Materials Characterization\& Engineering, 9(1), 57-65.

Coates, B., \& Argyropoulos, S. A. (2007). The effects of surface roughness and metal temperature on the heat-transfer coefficient at the metal mold interface. Metallurgical and Materials Transactions B, 38(2), 243-255. https://doi.org/10.1007/s11663-007-9020-y

Dong Y., Bu K., Dou Y. \& Zhang D. (2011). Determination of interfacial heat-transfer coefficient during investment casting process of single-crystal blades. Journal of Materials Processing Technology,211(12), 2123-2131. https://doi.org/10.1016/j.jmatprotec.2011.07.01 2

Dour, G., Dargusch, M., Davidson, C. \& Nef, A. (2005). Development of a non-intrusive heat transfer coefficient gauge and its application to high pressure die casting effect of the process parameters. Journal of Materials Processing Technology, 169(2), 223-233. https://doi.org/10.1016/j.jmatprotec.2005.03.02 6

Durat M., Nart E., Kayıkcı R. \& Özsert İ. (2006). Metal döküm kalıpların sonlu elemanlar yöntemiyle tekrarlı termal analizi. Timak-Tasarım Imalat Analiz Kongresi, (ss 549-557). Balıkesir. http://timak.balikesir.edu.tr/pdf/\%20549.pdf

Fluent M. (2018). Chapter 17: Modeling Solidification \& Melting; ANSYS, Inc.: Canonsburg, PA, USA. https://mae.iith.ac.in/ansys/files/scientific/fluent _tut/theoryguide_Solidification $\% 20$ and $\% 20$ melt ing.pdf

Gafur M.A., Haque M.N. \& Prabhu K.N. (2003). Effect of chill thickness and superheat on casting/chill interfacial heat transfer during solidification of commercially pure aluminum. Journal of Materials Processing Technology, 133(3), 257265. 0136(02)00459-4

Garza H.A. \& Miller R.A. (2003). The effects of heat released during fill on the deflections of die casting dies. Journal of Materials Processing Technology, 142(3), 648-658. https://doi.org/10.1016/S0924-0136(03)00685$\mathrm{X}$

Gozlan E. \& Bamberger M. (1987). Heat flow and solidification in a metal mould source. International Journal of Materials Research, 78(9), 677-682. https://doi.org/10.1515/ijmr1987-780911
Hallam C.P. \& Griffiths W.D. (2004). A model of the interfacial heat-transfer coefficient for the aluminum gravity die-casting process. Metallurgical and Materials Transactions B, 35(4), 721-733. https://doi.org/10.1007/s11663004-0012-x

Hamasaiid A., Dour G., Loulou T. \& Dargusch M.S. (2010). A predictive model for the evolution of the thermal conductance at the casting-die interfaces in high pressure die casting. International Journal of Thermal Sciences, 49(2), 365-372. https://doi.org/10.1016/j.ijthermalsci.2009.07.01 4

Ho, K., \& Pehlke, R. D. (1985). Metal-mold interfacial heat transfer. Metallurgical Transactions $B$, 16(3), 585-594.

Ilkhchy, A. F., Jabbari, M., \& Davami, P. (2012). Effect of pressure on heat transfer coefficient at the metal/mold interface of A356 aluminum alloy. International Communications in Heat and Mass Transfer, 39(5), 705-712. https://doi.org/10.1016/j.icheatmasstransfer.201 2.04.001

Ipek O. \& Koru M. (2011). Yüksek basınçlı döküm prosesinde kalıp sıcaklığına bağlı olarak dökümkalıp arayüzeyinde oluşan termal temas direncinin belirlenmesi. Isl Bilimi ve Tekniği Dergisi, 31(1), 45-57.

Looser R., Vivar M. \& Everett V. (2014). Spectral characterization and long-term performance analysis of various commercial heat transfer fluids (HTF) as direct-absorption filters for CPV$\mathrm{T}$ beam-splitting applications, Applied Energy, 113, 1496-1511. https://doi.org/10.1016/j.apenergy.2013.09.001

Loulou, T., Artyukhin, E. A. \& Bardon, J. P. (1999). Estimation of thermal contract resistance during the first stages of metal solidification process: II- experimental setup and results. International Journal of Heat and Mass Transfer, 42(12), 2129-2142 https://doi.org/10.1016/S00179310(98)00338-X

Michel F., Louchez P. R. \& Samuel F. H. (1995). Heat transfer coefficient during solidification of al-si alloys: effects of mold temperature, coating type and thickness. Transactions of The American Foundrymen's Society, 103, 275-283.

Reddy, A. V. \& Beckermann, C. (1993). Measurements of metal-mold interfacial heat transfer coefficients during solidification of $\mathrm{Sn}$ and $\mathrm{Sn}-\mathrm{Pb}$ alloys. Experimental Heat Transfer an International Journal, 6(2), 111-129. https://doi.org/10.1080/08916159308946449 
Sabau A.S. \& Wu Z. (2007). Evaluation of a heat flux sensor for spray cooling for the die casting processes. Journal of Materials Processing Technology, 182(1-3), 312-318. https://doi.org/10.1016/j.jmatprotec.2006.07.03 9

Sahin H.M., Kocatepe K., Kayıkçı R. \& Akar N. (2006). Determination of unidirectional heat transfer coefficient during unsteady-state solidification at metal casting chill interface. Energy Conversion and Management, 47(1), 19-34. https://doi.org/10.1016/j.enconman.2005.03.021

Santos C.A., Siqueira C.A., Garcia A. \& Quaresma J.M.V. and Spim J.A. (2004). Metal/Mold heat transfer coefficients during horizontal and vertical unsteady-state solidification of $\mathrm{Al}-\mathrm{Cu}$ and $\mathrm{Sn}-\mathrm{Pb}$ alloys. Inverse Problems in Science and Engineering, 12(3), 279-296. https://doi.org/10.1080/10682760310001598706

Silva, J. N., Moutinho, D. J., Moreira, A. L., Ferreira, I. L., \& Rocha, O. L. (2011). Determination of heat transfer coefficients at metal-mold interface during horizontal unsteady-state directional solidification of $\mathrm{Sn}-\mathrm{Pb}$ alloys. Materials Chemistry and Physics, 130(1-2), 179-185. https://doi.org/10.1016/j.matchemphys.2011.06. 032

Srinivasan M.N. (1982). Heat transfer coefficients at the casting-mould interface during solidification of flake graphite cast iron in metallic moulds. Indian Journal of Technology, 20 (4), 123-129.

Taha M.A., El-Mahallawy N.A., El-Mestekawi M.T. \& Hassan A.A. (2001). Estimation of air gap and heat transfer coefficient at different faces of $\mathrm{Al}$ and Al-Si casting solidifying in permanent mould. Materials Science and Technology, 17(9), 1093- 1101. https://doi.org/10.1179/026708301101511004

Zhang B., Maijer D.M. \& Cockcroft S.L. (2007). Development of a 3D thermal model of the low pressure die cast (lpdc) process of Al356 aluminum alloy wheels. Materials Science and Engineering: A, 464(1-2), 295-305. 